\title{
Asian Dust Storm Activity and Its Association with Atmospheric Circulation from 1995 to 2006
}

\author{
Jia-Yuh $\mathrm{Yu}^{1,{ }^{*}}$, Yi-Wen Wang ${ }^{2}$, and Cheng-Wei Chang ${ }^{2}$ \\ ${ }^{1}$ Department of Atmospheric Sciences, Chinese Culture University, Taipei, Taiwan, ROC \\ ${ }^{2}$ Graduate Institute of Earth Sciences, Chinese Culture University, Taipei, Taiwan, ROC
}

Received 26 August 2008, accepted 25 May 2009

\begin{abstract}
In this paper, Asian dust storm activity from 1995 to 2006 and the associated atmospheric circulation are examined using SYNOP data and the NCEP/NCAR reanalysis atmospheric data. Observations show that the Gobi Desert is the most frequent birthplace for severe dust events in Asia, accounting for approximately $58 \%$ of the total percentage, followed by about $32 \%$ from the Taklamakan Desert and nearly 10\% from the Loess Plateau. Climatologically, the existence of a large-scale dry zone over mid-latitudes of Asia during the Spring provides a favorable environment for the frequent occurrences of dust events and subsequent dust transport across Asia.

To provide a quantitative measure of Asian dust storm activity, a "dust activity index" (DAI) is defined in this study. The time series of yearly DAI shows that Asian dust storm activity manifested marked interannual variations during $1995 \sim 2006$. For an active year such as 2001, the magnitude of DAI (26986) is about a factor of $5 \sim 6$ larger than that in 1997 (4569). Our analyses show that such variations are closely connected to the position of EAT (East Asian Trough), rather than to its strength. In a year when the EAT was shifted westward (e.g., 2001), an east-west oriented low-high dipole appeared over Asia. This anomalous pressure dipole enhanced the prevailing northwesterly flows over Mongolia and northern China, resulting in a drier-than-normal atmosphere in favor of dust storm activity. On the contrary, in a year when the EAT was shifted eastward (e.g., 1997), a reverse dipole occurred, resulting in a wetter-than-normal atmosphere disfavoring dust storm activity. A SVD (singular value decomposition) analysis of the Asian synoptic circulation has shown that the connection between the pressure dipoles and the position of EAT is rather robust when dust storm activity is particularly strong (e.g., 2001, 2002, and 2006) or weak (e.g., 1997 and 1999).

Analyzing a large number of trajectories derived from the NOAA HYSPLIT model further suggests that dust aerosols arisen from the Gobi Desert and the Loess Plateau are likely to propagate eastward along the strong westerly flows. On the contrary, easterly flows occurring over the Taklamakan Desert incline dust aerosols there to slow westward propagation. Different geographical locations relative to the mean circulation and topography effect are responsible for such different patterns.
\end{abstract}

Key words: Asian dust storm activity, Atmospheric circulation, Trajectory analysis

Citation: Yu, J. Y., Y. W. Wang, and C. W. Chang, 2010: Asian dust storm activity and its association with atmospheric circulation from 1995 to 2006. Terr. Atmos. Ocean. Sci., 21, 375-391, doi: 10.3319/TAO.2009.05.25.01(A)

\section{INTRODUCTION}

Dust storms (or sand storms) are meteorological phenomena driven by gusty winds that occur when strong pressure gradients develop across a dry arid or semi-arid region where loose sands or soils are more prevalent (Glickman 1999). Essential conditions for the occurrence of dust storms

\footnotetext{
* Corresponding author

E-mail:jiayuh@atmos.pccu.edu.tw
}

include an immense dust (or sand) source, strong surface winds, and an unstable atmosphere (Zhao and Yu 1990; Yu et al. 2002). In the birthplaces of dust storms, strong surface winds are often excited by the passage of cold fronts, while an unstable atmosphere usually occurs after rapid solar heating close to the ground. Therefore, intensive dust storms tend to take place in the afternoon when solar heating has reached its peak value (Iwasaka et al. 1983; Lin and Yu 2005). 
Major dust-source regions in Asia are located at midlatitudes, including the Gobi Desert, Loess Plateau and Taklamakan Desert. The Gobi Desert, which covers areas in southern Mongolia and northern China, is perhaps the largest dust-source region in Asia. It has an extreme climate characterized by rapid changes of temperature throughout the day and extreme dryness throughout the year. The Loess Plateau, surrounded by the great bend of the Yellow River, is covered by very fine dusty soils that have been constantly deposited by prevailing winds on the plateau over the ages. Since the above regions are situated in the pathway of cold air outbreaks from the Siberia-Mongolia region during the winter and spring seasons, they have been recognized as two major birthplaces of intensive dust storms in East Asia (Chen and Chen 1987; Yu et al. 2002). The Taklamakan Desert, a great basin desert of central Asia in the Xinjiang Uyghur Autonomous Region of China, is another birthplace of dust storms. While the desert is surrounded by high mountains and located to the southwest of Siberia-Mongolia high pressure system during the winter and spring seasons, dust storms occurring there are generally modest and nearly stationary (Chen and Chen 1987).

It has recently been recognized that dust clouds arising from intensive dust storms are a major source of natural aerosols in the atmosphere whose direct and indirect radiative effects may exert significant impact on the earth's climate (Haywood and Boucher 2000; Collins et al. 2002) as well as on the planet's ecology (Griffin and Kellogg 2004). Due to their pronounced impact on the earth's environment, growing concerns about the threat from intensive dust storms have resulted in a rapid development of new techniques for dust cloud monitoring, including satellite data retrieval techniques (Kaufman et al. 2002; Liu and Lin 2004) and Lidar profiling (Chiang et al. 2004; Nee et al. 2007) of dust aerosols.

Recent studies have shown that dust storms occurring in East Asia often experience long-distance transport of huge dust clouds to downstream areas (Chou et al. 2004; Nee et al. 2007; Zhao et al. 2007). Huge dust clouds generated by dust storms can sometimes travel thousands of kilometers across the Pacific to impact North America (Hacker et al. 2001; Husar et al. 2001; Uno et al. 2001). Even though eastward movement seems to be the major path for Asian dust transport, emerging evidence has shown that southward dust transport is feasible (Chen et al. 2004; Lin et al. 2004). A recent study by Lin and $\mathrm{Yu}$ (2005) indicated that a minor surface split high separated from the major Siberia-Mongolia high plays a crucial role in the process of southward dust transport. As the surface split high moves offshore, the northerly winds located at its leading edge carry dust aerosols southward. They further pointed out that the amount of dust aerosols traveling to the south highly depends on latitudes of the surface split high. As the surface split high moves offshore at lower latitudes (e.g., $<30^{\circ} \mathrm{N}$ ), enormous dust aerosols can penetrate deep into subtropical latitudes to impact Taiwan (Lin and Yu 2005) and even Hong Kong (Fang et al. 1999).

Due to the lack of high-quality observations, long-term (i.e., a period of several decades) Asian dust storm variations were rarely documented until recently. Sun et al. (2001) used the data compiled from 174 meteorological stations in China to analyze the spatial and temporal characteristics of dust storm systems during the period $1960 \sim 1999$. They found that active frontal systems associated with the Mongolian cyclonic depression are responsible for the frequent occurrences of dust storm systems in China. By comparing surface and $500 \mathrm{hPa}$ airflows, they also argued that dust particles entrained to the air from the Taklamakan Desert can be lifted to a higher elevation $(>5000 \mathrm{~m})$ and then transported a long distance $(\sim 5000 \mathrm{~km})$ by the westerly flows, while dust particles entrained from the Gobi Desert can only be lifted to an elevation of $<3000 \mathrm{~m}$ and are likely to produce impacts mainly at regional scales. We note that their argument appears to contradict an earlier study by Chen and Chen (1987) who presented a completely reverse conclusion. A trajectory analysis will be carried out in this paper to clarify the contradiction.

Although dust storms are caused by weather disturbances, their seasonal to interannual variability, however, is controlled mainly by atmospheric circulation or namely climate, which includes the Artic Oscillation (Gong et al. 2006), the Pacific/North American pattern (Gong et al. 2007), the El Niño/Southern Oscillation (Yoshino 2002; Gao et al. 2003), decadal climate change (Qian et al. 2002), and even global warming (Wei et al. 2005). Despite the importance of climate control on dust storm activity, their physical links are not fully understood thus far. This paper aims to address the connection between Asian dust storm activity and the atmospheric circulation at both planetary and synoptic scales in a climatological sense. In section 2, data sources used in this study are introduced, including the international code for land surface weather reports (also known as "SYNOP data"), the NCEP (National Center for Atmospheric Research) reanalysis atmospheric data, and the model derived trajectories. A "dust activity index" (DAI) is also defined in this study as a measure of Asian dust storm activity. Section 3 describes temporal and spatial features of Asian dust events and the associated atmospheric circulation patterns. To portray the climate control on Asian dust storm activity, the atmospheric circulation patterns of two distinct years (i.e., 1997 and 2001) are compared in section 4. Possible climate controls responsible for the interannual variability of DAI are also discussed. Section 5 examines the dominant synoptic circulation modes in connection to Asian dust storm activity. Section 6 provides a detailed analysis of the trajectories released from major dust-source regions to project the potential paths of dust transport in Asia. Section 7 summarizes major findings in this study. 


\section{DATA AND METHOD}

\subsection{SYNOP Data}

A 3-hourly dataset compiled from the international code for land surface weather reports (also known as "SYNOP data" or "SYNOP code") from 1995 to 2006 is used to measure dust storm activity across Asia. The SYNOP code is a codification system designed for synoptic observations of weather events which has been used by meteorological organizations all over the world for several decades (Djuric 1994). In this study, the SYNOP data has been quality-controlled to ensure continuous observations of dust events during the study period. Figure 1 shows the geographical locations of 822 meteorological stations used in this study. We consider the domain within $\left(20 \sim 50^{\circ} \mathrm{N} / 80 \sim 140^{\circ} \mathrm{E}\right)$ where most dust events in Asia are reported. As shown in Fig. 1, weather stations are distributed more densely over eastern China, the Korean Peninsula, and Japan, where large populations reside. Only approximately 150 weather stations are scattered over the vast western areas of China and Mongolia.

In this study, the "present weather" group in the SYNOP code is adopted to measure the spatial and temporal characteristics of dust events occurring in Asia. In observational practice of weather (Djuric 1994), 10 types of dust stormrelated events are encoded in the "present weather" group. Following Goudie and Middleton (1992), these dust events are classified into three categories according to the strength, including dust haze, blowing dust, and dust storm. The dust haze, corresponding to codes $06 \sim 09$ in the "present weather" group, is referred to as the state of dust particles homogeneously suspended in the air by winds with horizontal visibility less than $10 \mathrm{~km}$. The blowing dust, corresponding to codes $30 \sim 32$ in the "present weather" group, is referred to as the state where dust is raised above the ground locally through strong winds with horizontal visibility being reduced to $1 \sim 10 \mathrm{~km}$. The dust storm, corresponding to codes $33 \sim 35$ in the "present weather" group, is the result of strong turbulent wind systems entraining dust particles into the air with horizontal visibility lower than $1 \mathrm{~km}$. We note that dust storm and blowing dust are severe dust events which are often observed over the dust source regions, while dust haze is observed mainly in the downstream areas owing to dust transport. In most studies (Qian et al. 2002; Tien et al. 2007), these dust events are all recognized as parts of the dust storm system when considering the accumulated dust durations.

\subsection{Atmospheric Data}

The NCEP/NCAR (National Center for Climate Prediction/National Center for Atmospheric Research) atmospheric data is also used to portray the background atmospheric circulation during Asian dust storm season. The NCEP/NCAR reanalysis data uses a state-of-the-art analysis/forecast system to perform data assimilation using past data from 1948 to

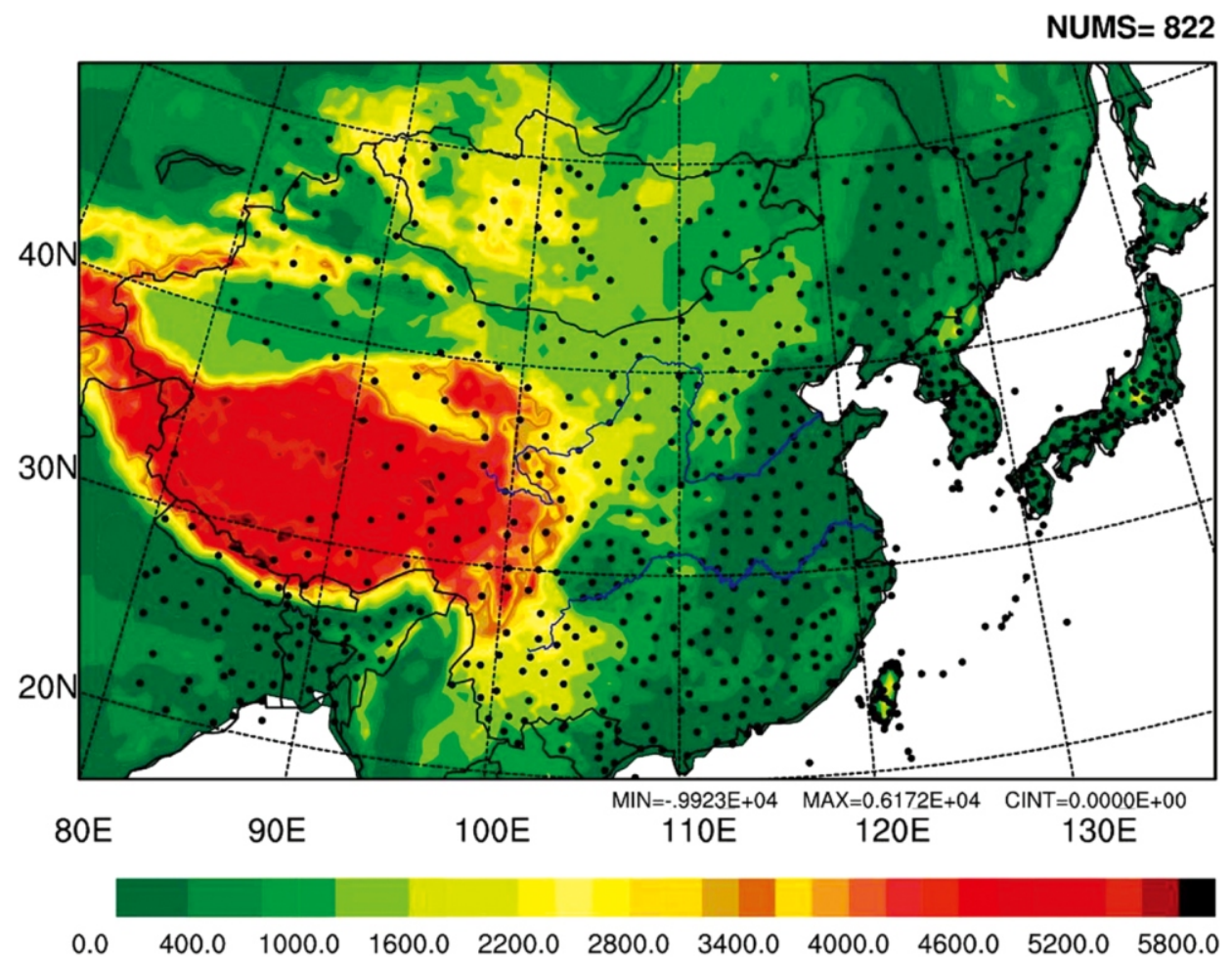

Fig. 1. Geographical locations of 822 land surface weather stations (shown by dots) used in this study. Topography (shown by color shading) is also displayed in the figure for reference. 
present. It provides major atmospheric parameters (e.g., geopotential height, relative humidity, horizontal winds, etc.) at 17 pressure levels from 1000 up to $10 \mathrm{hPa}$ with a horizontal resolution of $2.5^{\circ} \times 2.5^{\circ}$. Detailed descriptions of the dataset can be found in Kalnay et al. (1996).

\subsection{NOAA HYSPLIT Forward Trajectory Data}

To project the potential paths of dust transport in Asia, a large number of forward trajectories derived from NOAA (National Oceanic and Atmospheric Administration) HYSPLIT (HYbrid Single-Particle Lagarangian Integrated Trajectory) model are analyzed. The NOAA HYSPLIT model is the newest version of a complete system for computing simple air parcel trajectories to complex dispersion and deposition simulations (Draxler and Hess 1998). The forward and backward trajectories of the HYSPLIT model have been recognized as a powerful tool for the analysis of dust cloud transport (Nee et al. 2007).

In this study, 4-day forward trajectories set free daily at 1400 LT from three major dust-source regions are calculated during the Spring (March May) of $1995 \sim 2006$. Specifically, trajectories are set free from the locations at $\left(45^{\circ} \mathrm{N}\right.$, $\left.105^{\circ} \mathrm{E}\right),\left(38^{\circ} \mathrm{N}, 108^{\circ} \mathrm{E}\right)$, and $\left(39^{\circ} \mathrm{N}, 82^{\circ} \mathrm{E}\right)$, respectively. Trajectories set free from $\left(45^{\circ} \mathrm{N}, 105^{\circ} \mathrm{E}\right)$ are used to project potential paths of dust transport from the Gobi Desert. Similarly, trajectories set free from $\left(38^{\circ} \mathrm{N}, 108^{\circ} \mathrm{E}\right)$ and $\left(39^{\circ} \mathrm{N}\right.$, $82^{\circ} \mathrm{E}$ ) are employed to project potential paths of dust transport from the Loess Plateau and the Taklamakan Desert, respectively. All trajectories are set free at the 10-meter level to avoid frequent terminations of trajectory calculation due to terrain blocking.

\subsection{Dust Activity Index}

In order to provide a quantitative measure of Asian dust storm activity, a "dust activity index" (DAI) is defined by summing up durations of all dust reports occurring at each station within the domain $\left(80 \sim 140^{\circ} \mathrm{E}, 20 \sim 50^{\circ} \mathrm{N}\right)$ using the 3 -hourly SYNOP data. In computing DAI, each dust report stands for a dust duration of 3 hours. In practice, DAI represents the accumulated dust durations (in units of hours) across Asia while its annual magnitude may signify the strength of Asian dust storm activity in that year. We note that the DAI defined here is very similar to the "accumulated Asian dust days" documented in Tien et al. (2007) in which they used dust reports from 98 stations over China to characterize the strength of yearly Asian dust activity. In this study, 822 meteorological stations across Asia are adopted to calculate the DAI. Unlike some studies that consider dust durations only in dust-source regions (e.g., Yoshino 2002; Gao et al. 2003), the DAI considers dust durations within the domain shown in Fig. 1 such that the contribution from dust transport can be included as well.

To test the sensitivity of DAI against other remote sensing techniques, a space-time variability analysis of the TOMS aerosol index (AI) is presented in Appendix A as a comparison. The result shows that while the time series pattern of TOMS AI is rather similar to the DAI, its year-to-year variability seems to be far below than those in DAI. Since the DAI employs data from in situ observations of dust events, it should describe their variations better than other remote sensing techniques.

\section{CLIMATOLOGICAL CHARACTERISTICS}

\subsection{Climatology of Dust Storm Activity}

Figure 2 shows the annual cycle of monthly DAI averaged over $1995 \sim 2006$ which depicts the seasonal cycle of Asian dust storm activity. Although dust events can occur through the year, Spring (March, April, and May) stands out above the rest as the most active season, accounting for over $65 \%$ of the annual DAI. Despite sparser distribution of weather stations, dust-source regions still contribute approximately $71 \%$ of the annual DAI, while the downstream areas contribute the remaining 29\%. Since Spring accounts for most of the annual DAI, we therefore focus the analyses solely on the Spring composite hereafter throughout the paper except otherwise mentioned.

Figure 3 displays the time series of yearly DAI during $1995 \sim 2006$ which describes the degree of interannual variability of Asian dust storm activity. We note that the magnitudes of DAI exhibit marked interannual variations. For dust storm active years such as 2001 and 2002, the magnitudes of DAI (26986 and 24231, respectively) are about a factor of

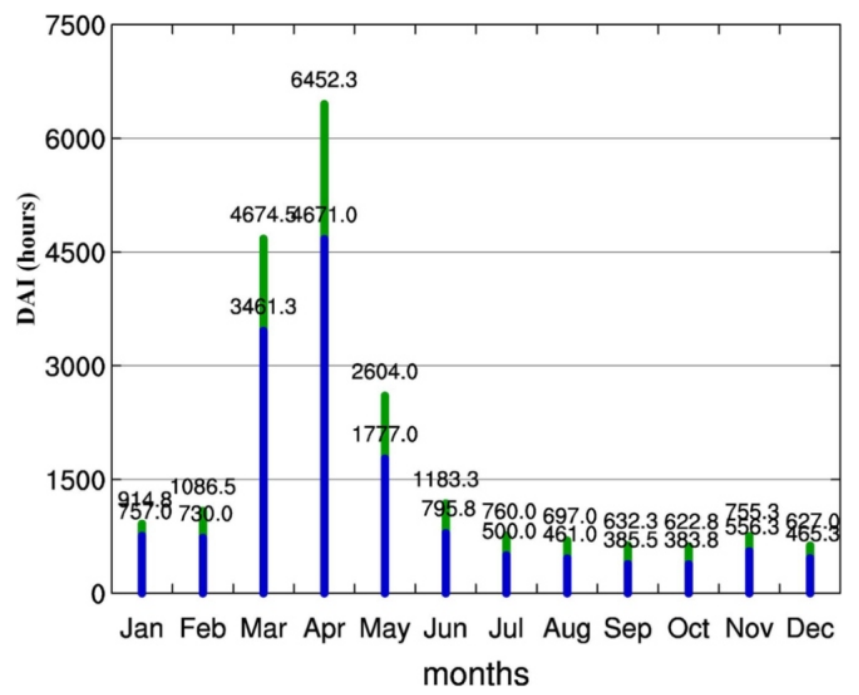

Fig. 2. Annual cycle of monthly DAI (dust activity index) averaged over $1995 \sim 2006$. Dark portions of the bars denote contributions from dust-source regions while gray portions represent contributions elsewhere in Asia. 


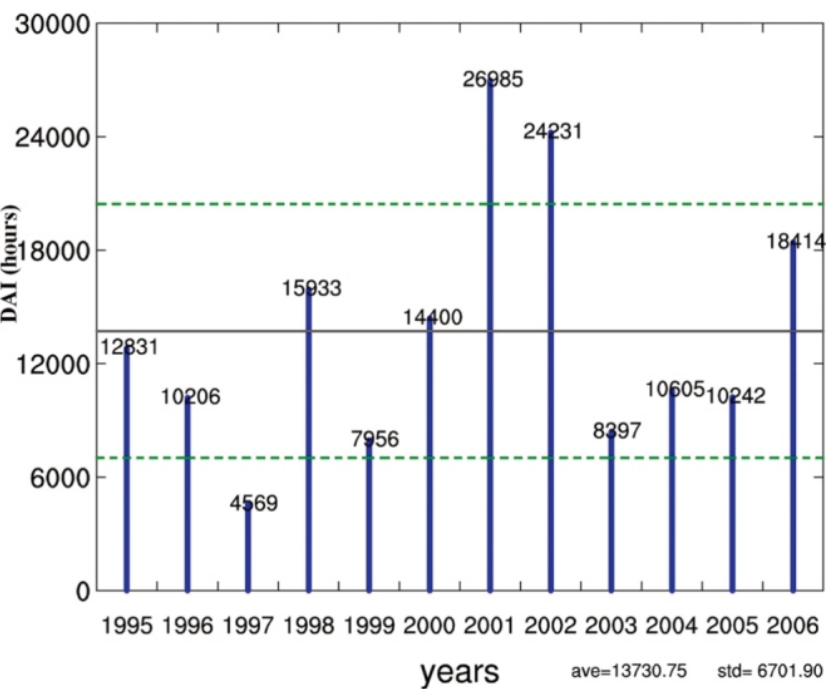

Fig. 3. Same as in Fig. 2, but for the time series of yearly DAI. The annual DAI is derived by summing up monthly DAI during Spring. The horizontal solid line represents the mean while the upper and lower dashed lines denote one standard deviation above and below the mean, respectively.

$5 \sim 6$ larger than that in 1997 (4569). Although land cover change (e.g., vegetation, anthropogenic land use, etc.) in Asia can be rather significant on centennial time scales (Ramankutty and Foley 1999), its year-to-year variability is generally far below the observed dust storm variations (Nemani and Running 1995; Zhang et al. 2003; Wei et al. 2005). Therefore, the result shown in Fig. 3 suggests a strong climate control on Asian dust storm activity. The climate patterns responsible for such a strong interannual variability in Asian dust storm activity will be examined in sections 4 and 5 .

Figure 4 displays the occurrence frequency of dust events averaged over $1995 \sim 2006$. To elaborate, dust events of various strengths are displayed separately. Climatologically, the Gobi Desert appears to be the most frequent source region for severe dust events with a seasonal occurrence frequency in the range of $2 \sim 4$ and $4 \sim 12$ days for the dust storm (Fig. 4a) and the blowing dust (Fig. 4b) categories, respectively. Frequent severe dust events are also observed in the Taklamakan Desert with a seasonal occurrence frequency in the range of $1 \sim 2$ and $2 \sim 4$ days for the dust storm and the blowing dust categories, respectively. The occurrence frequency of dust haze category (Fig. 4c), however, reveals a rather different picture. The Taklamakan Desert now becomes the most frequent source region with a seasonal occurrence frequency of $20 \sim 60$ days. Frequent dust hazes are also observed in the Gobi Desert and the Loess Plateau with a seasonal occurrence frequency of $7 \sim 20$ days. Surprisingly, dust hazes are occasionally observed almost everywhere in Asia with a seasonal occurrence frequency of $1 \sim 6$ days, a clear evidence of dust transport across Asia.
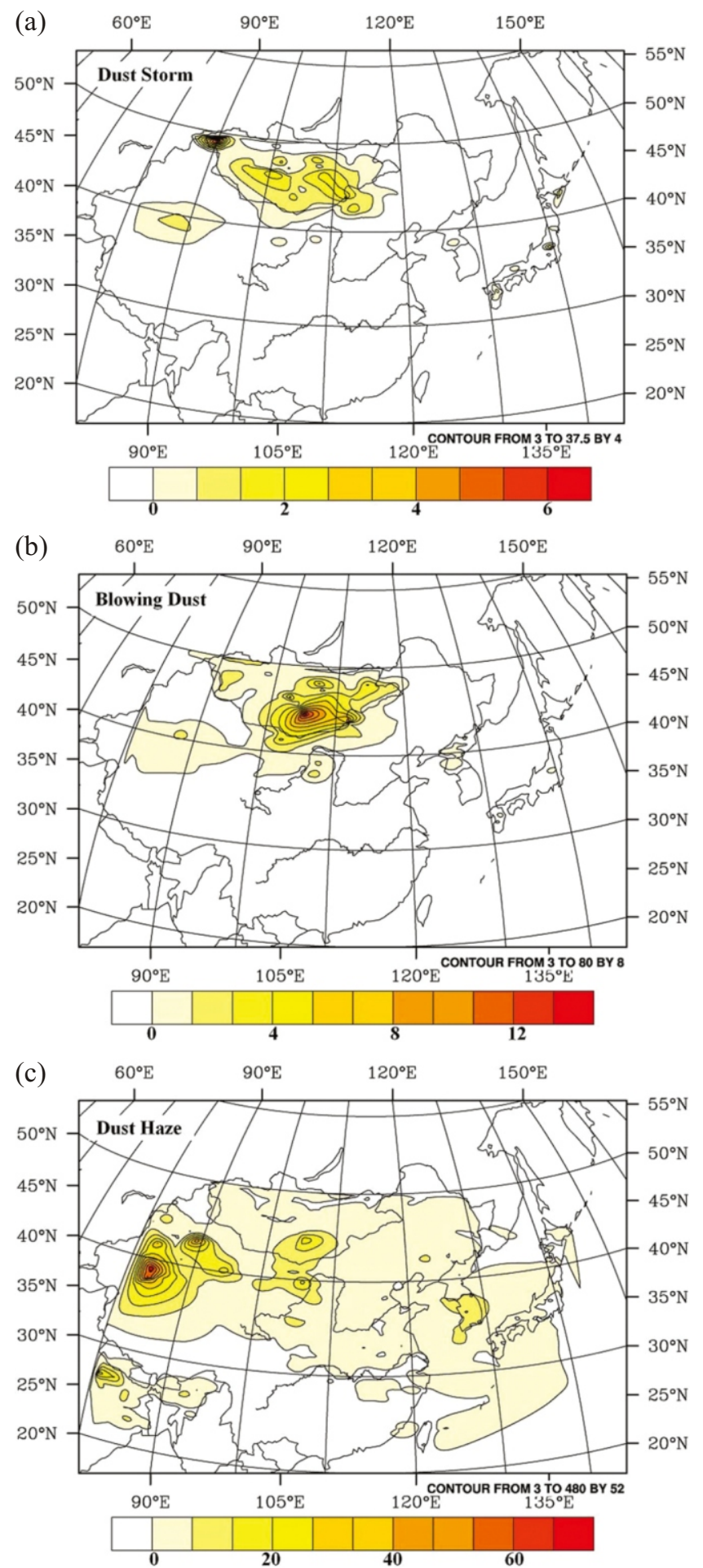

Fig. 4. Occurrence frequencies of dust storm (a), blowing dust (b), and dust haze (c) in Asia. Occurrence frequencies are averaged over 1995 2006 (in units of days).

In sum, the Gobi Desert is the most frequent birthplace for severe dust events during 1995 2006, accounts for approximately $58 \%$ of the total percentage, followed by about $32 \%$ from the Taklamakan Desert, and nearly $10 \%$ from the Loess Plateau. 


\subsection{Mean Atmospheric Circulation}

To understand the background atmospheric circulation favoring dust storm occurrences, Fig. 5 displays the synoptic circulation patterns in lower troposphere at 1000, 850, and $700 \mathrm{hPa}$ levels, respectively. At first sight, we notice the existence of a large-scale dry zone $(\mathrm{RH}<40 \%)$ situated over mid-latitude Asia. At $1000 \mathrm{hPa}$ level (Fig. 5c), major dust-source regions, such as the Gobi Desert, the Loess Plateau, and the Taklamakan Desert, are all covered by the dry zone. In contrast, southern China, the Korean Peninsula, and Japan are capped by a moist atmosphere $(\mathrm{RH}>$ $70 \%$ ). We note that the appearance of a quasi-stationary East Asia Trough (EAT) to the east of Asian continent plays an important role in the maintenance of the aforementioned dry zone. Precisely speaking, it is the strong northwesterly
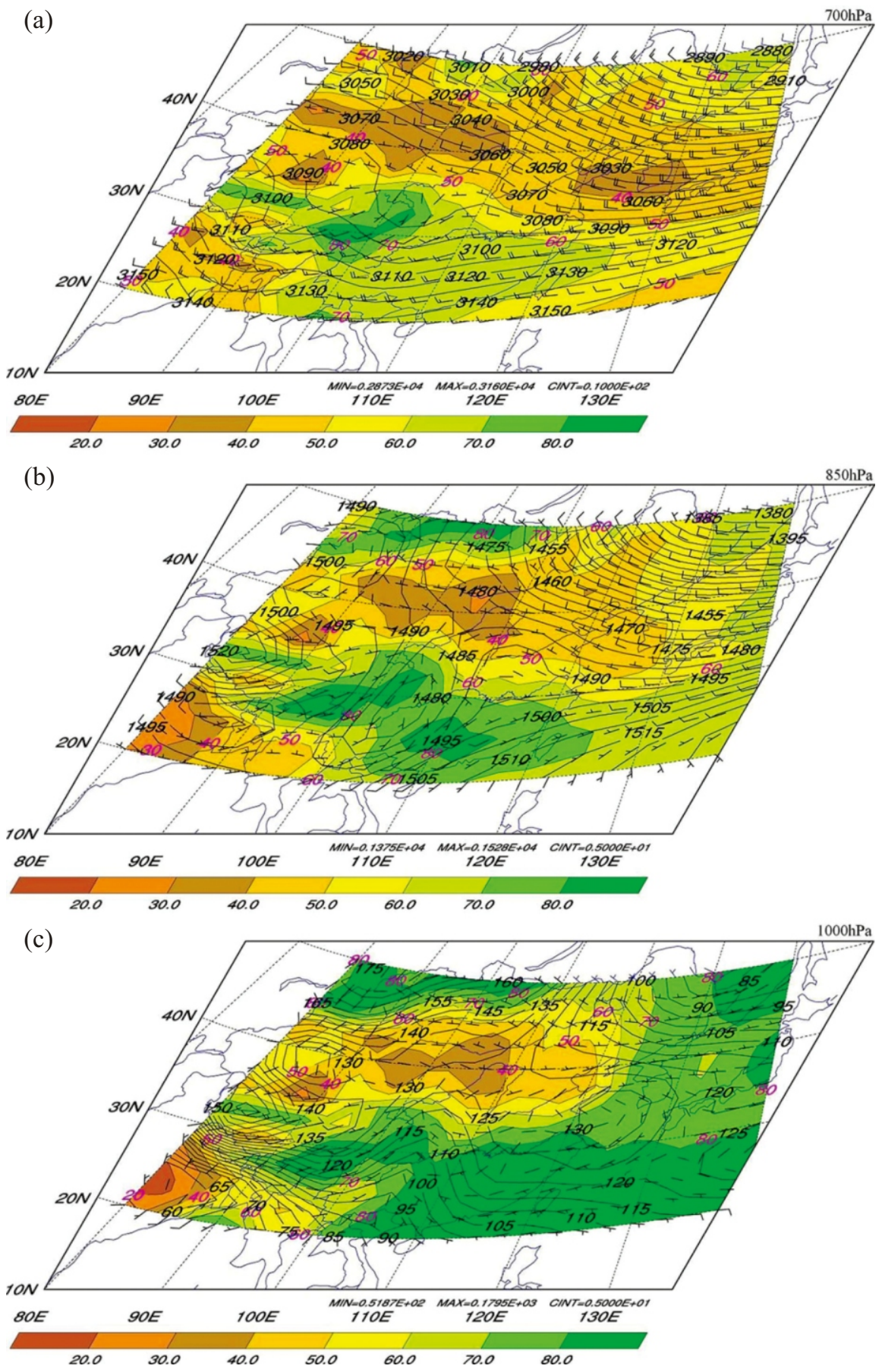

Fig. 5. Spring circulation patterns in lower troposphere over East Asia at $700 \mathrm{hPa}(\mathrm{a}), 850 \mathrm{hPa}$ (b), and $1000 \mathrm{hPa}$ (c), respectively. The geopotential height (contours), winds (flags), and relative humidity (colors) are displayed simultaneously. 
flows developed behind EAT (see Figs. 5a and b) that bring Siberia-Mongolia's dry and cold air southeastward to maintain the dry zone. We also note that the dry zone and the associated northwesterly airflows strengthen as the altitude increases, providing a favorable environment for dust transport within the troposphere (due to less chance of wet deposition). Since the strength and position of EAT exhibit substantial fluctuations from year to year (Jhun and Lee 2004), how their changes influence Asian dust storm activity is an important issue that requires further examinations. Details are discussed at length in sections 4 and 5.

\section{COMPARISONS BETWEEN 1997 AND 2001}

As shown in Fig. 3, 1997 and 2001 are two extreme years of abnormal dust storm activity during $1995 \sim 2006$. To understand how atmospheric circulation influences Asian dust storm activity, we start by comparing spatial distributions of dust events and the associated atmospheric circulations between 1997 and 2001 in this section.

\subsection{Dust Storm Activity}

Figure 6 displays the annual cycle of monthly DAI for both 1997 and 2001. As shown in the figure, dust events occurred much more frequently in 2001 than in 1997. Major differences of DAI appear in Spring (March, April, and May). Differences of DAI in other seasons seem to be relatively small, suggesting a drastic change of atmospheric circulation between 1997 and 2001 particularly in the Spring.

Figure 7 compares the occurrence frequency of dust events estimated at each weather station between 1997 and 2001. Striking differences are noted when we compare plots

(a)

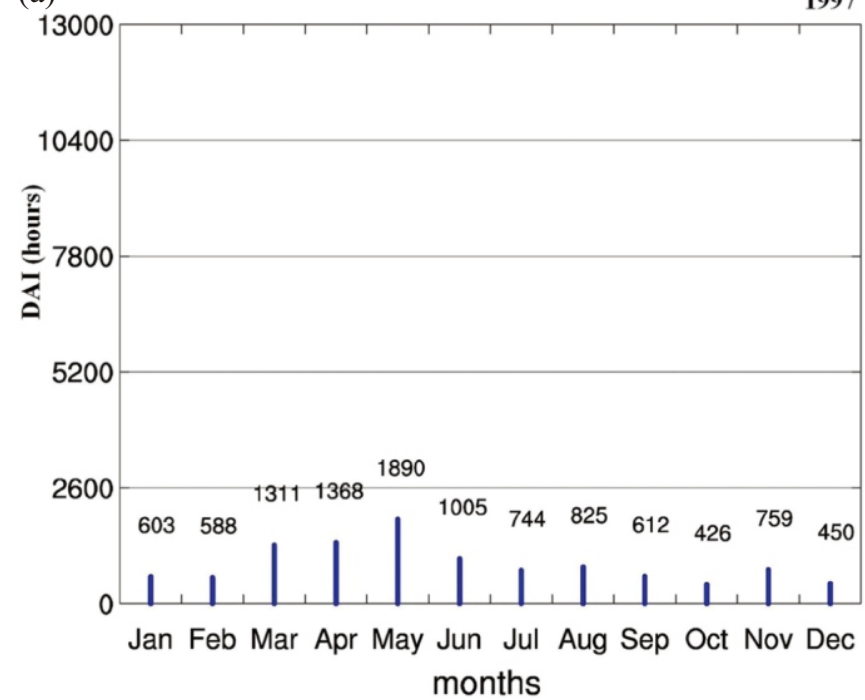

from 1997 (Figs. 7a, c, e) with plots from 2001 (Figs. 7b, d, f). During the Spring of 2001, frequent severe dust events (dust storm and blowing dust) occurred over the Gobi Desert, the Loess Plateau, and the Korean Peninsula. Several stations in the Gobi Desert even reported severe dust events spanning over 20 days. We also note that, except over dust-source regions, frequent dust hazes can be found almost everywhere in Asia, a vivid evidence of massive dust transport in 2001. On the contrary, dust storm activity appeared to be rather dormant during the Spring of 1997 (see Figs. 7a, c, e). Occasional dust events (blowing dust or dust haze) were observed only in the eastern Mongolia and Chinese Xinjiang and the evidences of dust transport (dust hazes) were sparsely reported in the downstream areas.

Since gusty winds are the major driving force entraining dust aerosols into the air, Fig. 8 thus compares the occurrence frequency of gales (wind speed $\geq 34$ knots) between 1997 and 2001. Gales rarely occurred in the Spring of 1997 (Fig. 8a) except over eastern Mongolia, which is consistent with the sparse distribution of dust events shown in Figs. 7a, c, and e. In contrast to 1997, the gales occurred much more frequently in the Spring of 2001, in particular, over the Gobi Desert and the northern Loess Plateau, which is again consistent with the frequent occurrence of dust events shown in Figs. 7b, d, and $\mathrm{f}$.

\subsection{Atmospheric Circulation}

Figure 9 compares synoptic circulation patterns in the lower troposphere between 1997 and 2001. To enhance their differences, the anomalous fields (climatology subtracted) are displayed instead of the total fields. During the Spring of 1997 (Figs. 9a, c, e), a pressure dipole appeared over Asia with a high anomaly in northern Mongolia and a low anom-

(b)

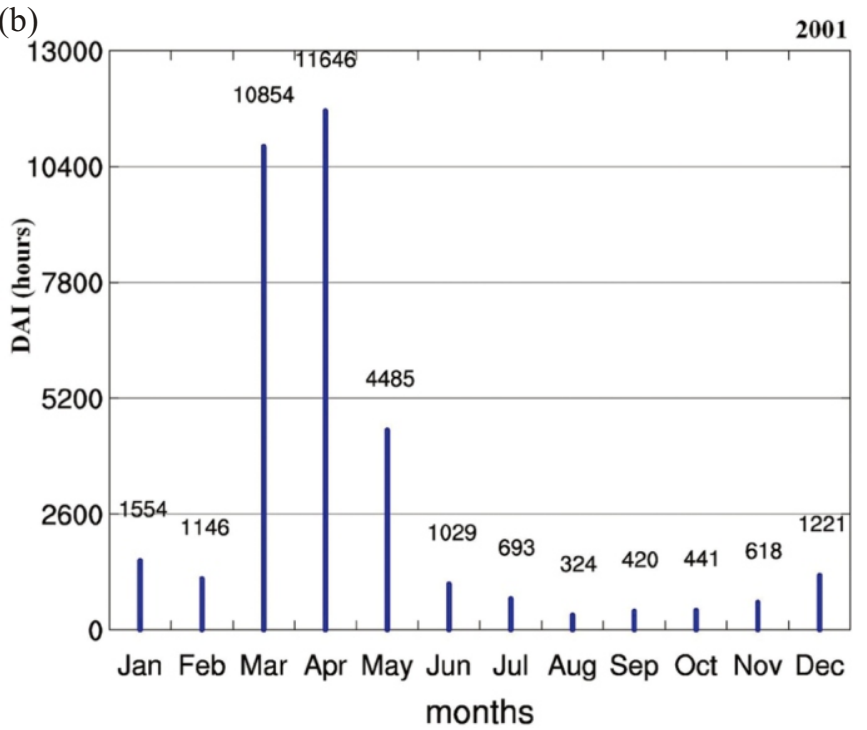

Fig. 6. Annual cycle of monthly DAI for 1997 (a) and 2001 (b). 
(a)

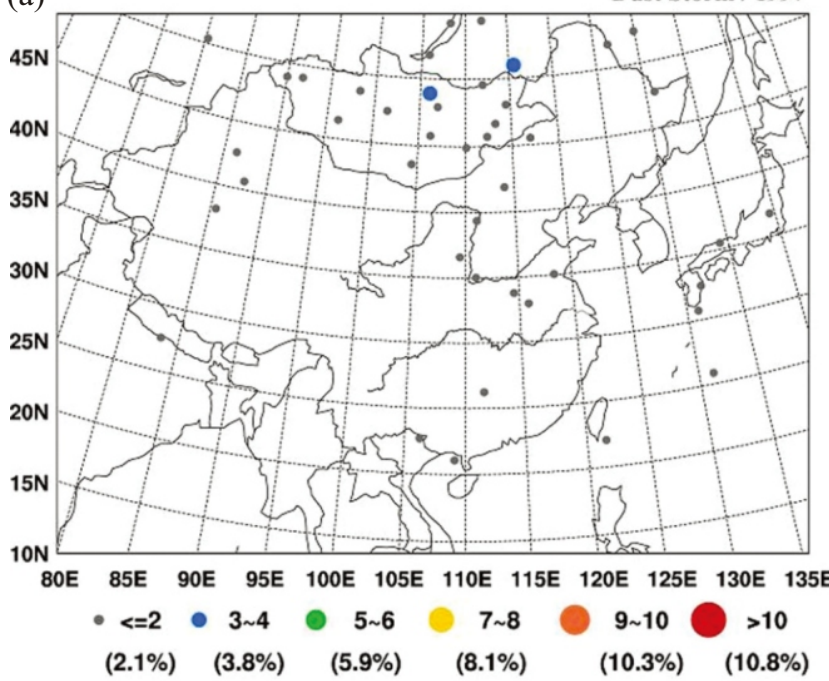

(b)

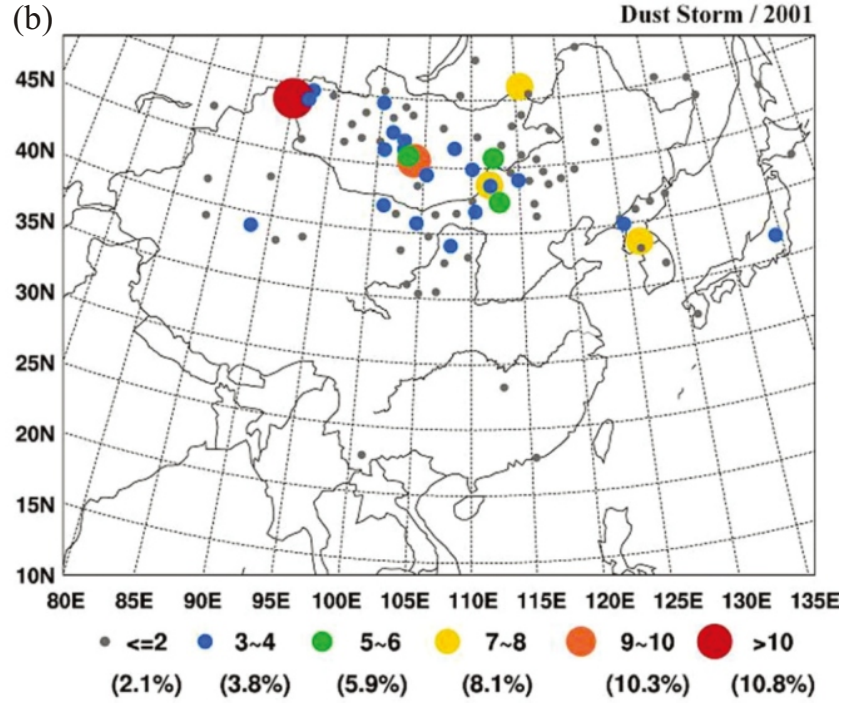

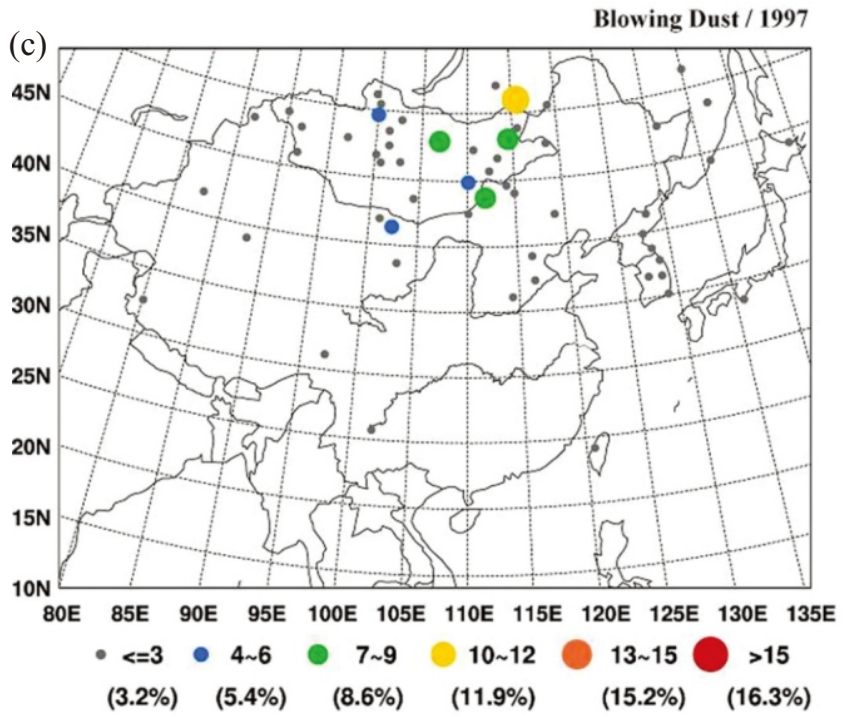
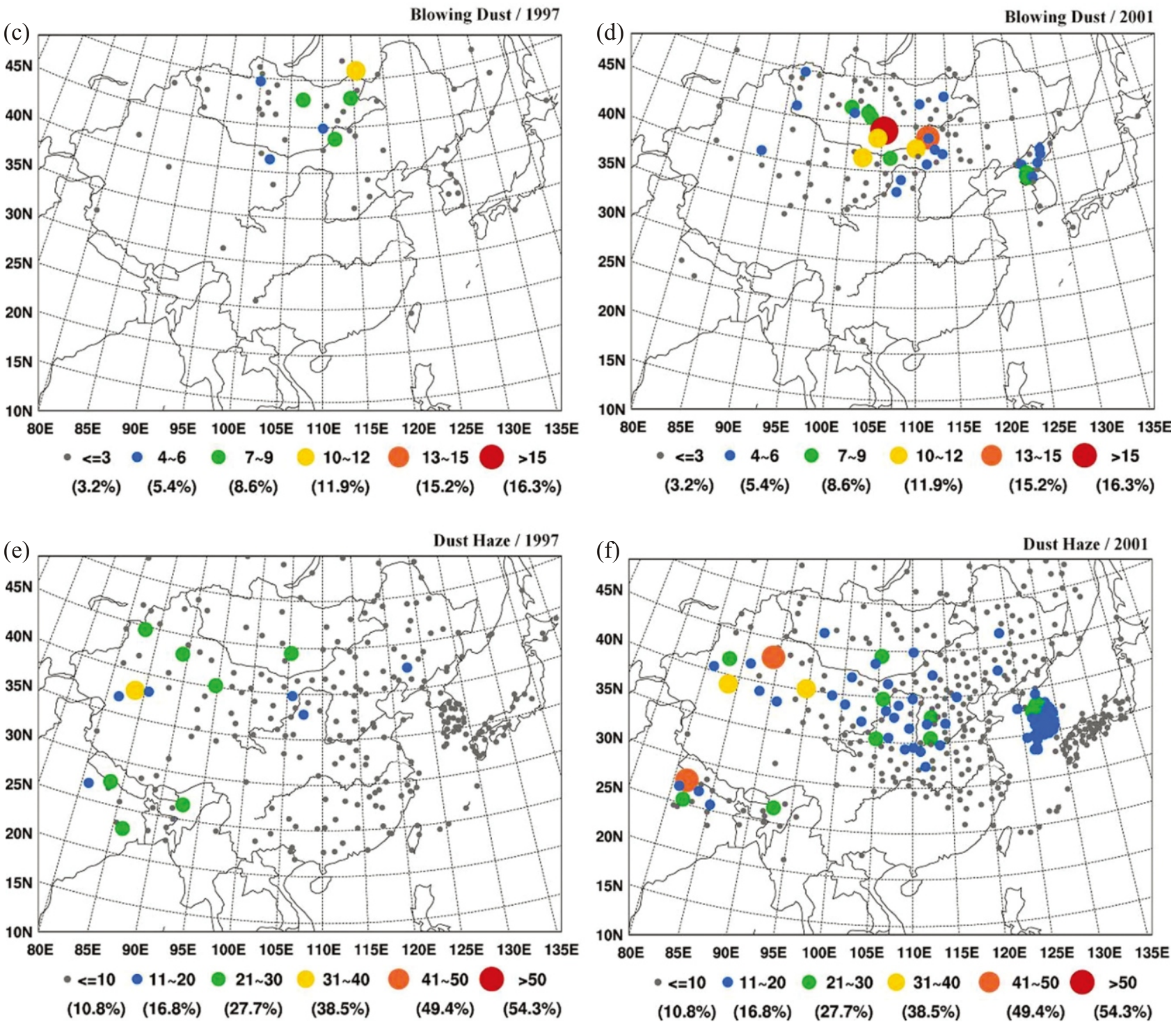

Fig. 7. The occurrence frequency of dust events evaluated at each weather station during the Spring of 1997 [(a), (c), (e)] and 2001 [(b), (d), (f)]. Dust events of various strengths are displayed separately, including dust storm [(a), (b)], blowing dust [(c), (d)], and dust haze [(e), (f)]. The occurrence frequency is in units of days or percents (in parenthesis) with magnitudes symbolized by the size of circle. 
(a)
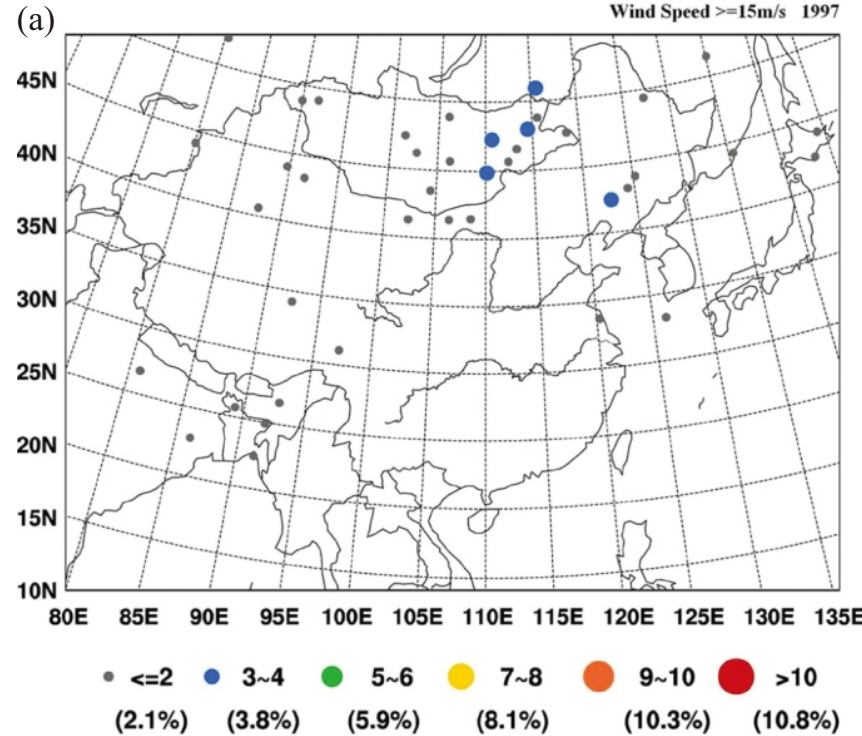

(b) Wind Speed $>=15 \mathrm{~m} / \mathrm{s} 2001$

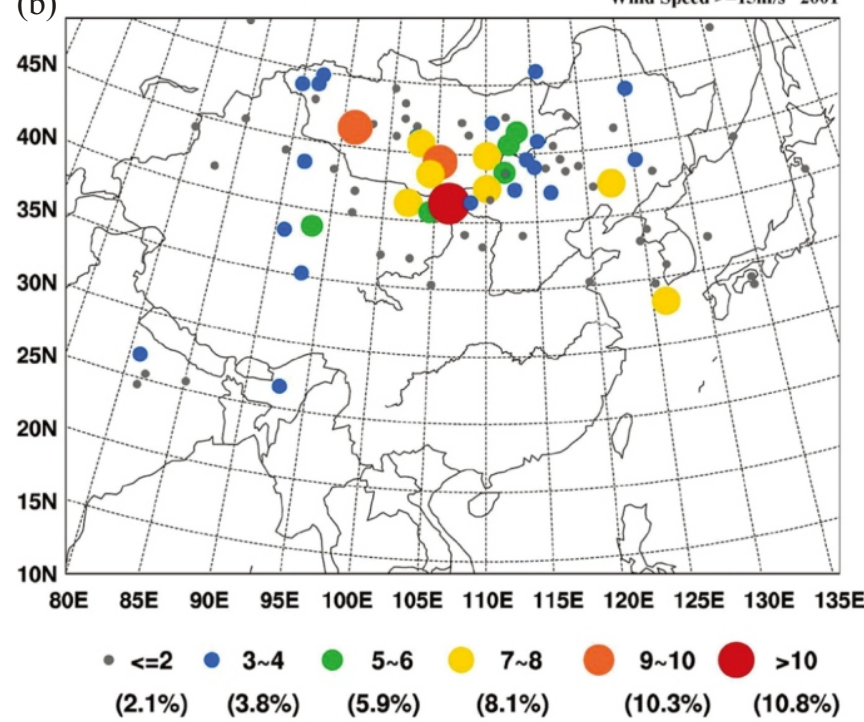

Fig. 8. Same as in Fig. 7, but for the occurrence frequency of strong winds (gales) during the Spring of 1997 (a) and 2001 (b).
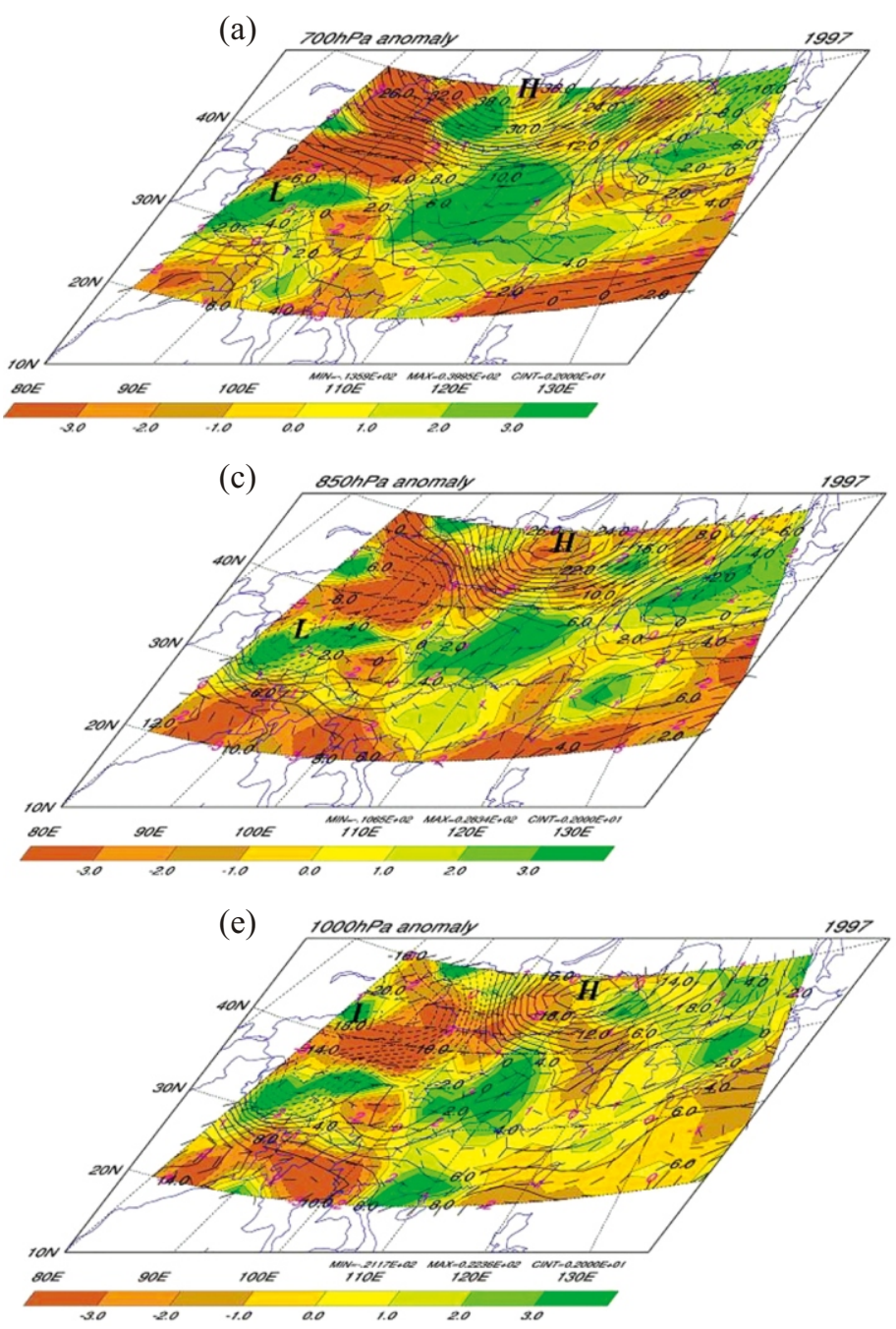
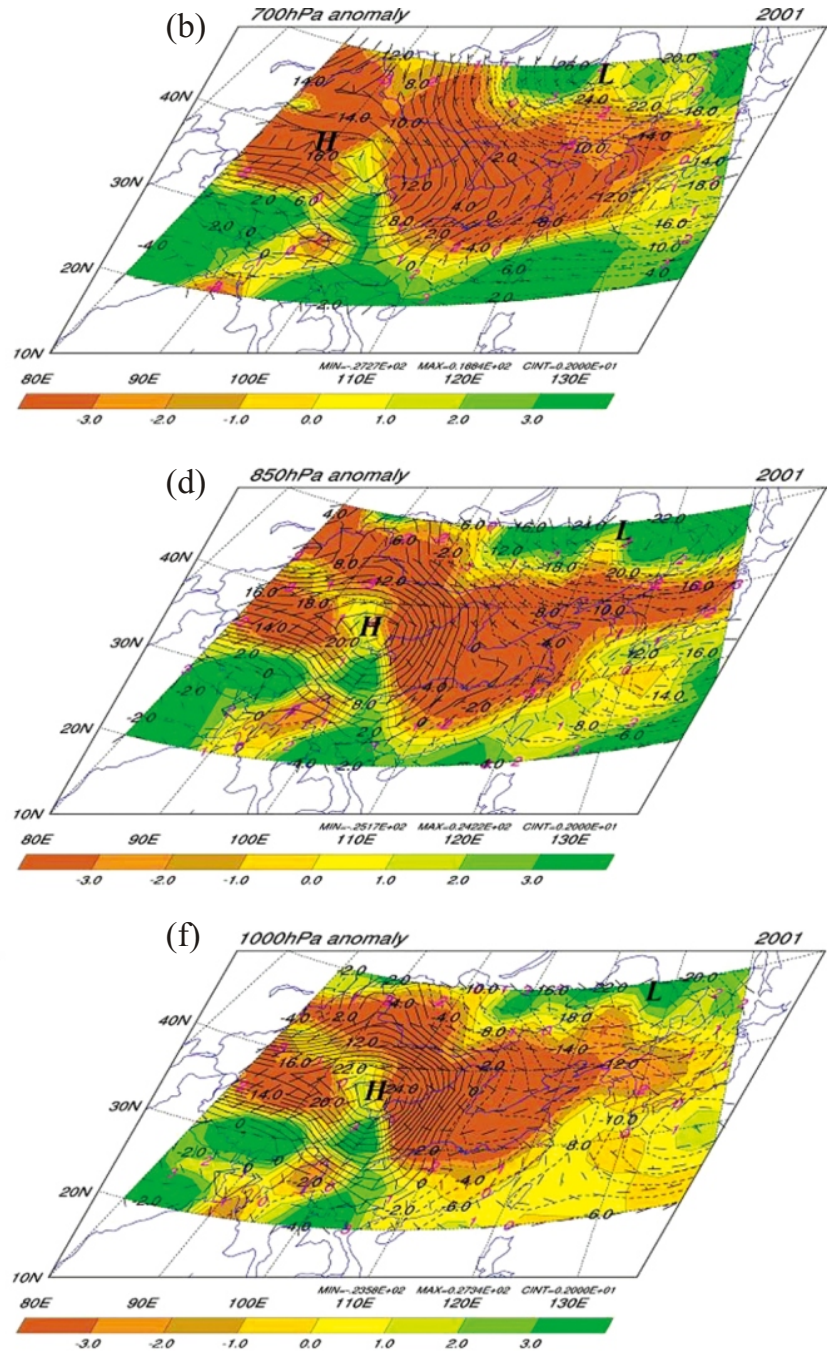

Fig. 9. Same as in Fig. 5, but for the anomalous circulation patterns for 1997 [(a), (c), (e)] and 2001 [(b), (d), (f)]. 
aly in Xinjiang. This east-west oriented high-low dipole introduced anomalous easterly flows over southern Mongolia and northern China. When superimposed on the mean circulation (see Fig. 5), the prevailing northwesterly flows over southern Mongolia and northern China were immediately weakened, resulting in a wetter-than-normal atmosphere and a quiet dust storm season. During the Spring of 2001 (Figs. 9b, d, f), the dipole pattern reversed in sign with a low anomaly in northeastern China and a high anomaly in Xinjiang. In association with this east-west oriented lowhigh dipole, the prevailing northwesterly flows over southern Mongolia and northern China were directly enhanced, resulting in a drier-than-normal atmosphere and an extremely active dust storm season.

To illustrate how these distinct pressure dipoles are maintained, a broader general circulation view is required. In Fig. 10, planetary circulation patterns at $500 \mathrm{hPa}$ level between 1997 and 2001 are compared. The $500 \mathrm{hPa}$ level is selected here because it exhibits an excellent mix of smallscale and large-scale systems which allows us to link the upper-level flows to surface synoptic systems. During the Spring of 1997 (Fig. 10a), the planetary circulation manifested a typical zonal wavenumber 3 structure with the position of $\mathrm{EAT}^{1}$ at approximately $150^{\circ} \mathrm{E}$. Strong westerly flows (i.e., jetstreams) developed near EAT between 35 $45^{\circ} \mathrm{N}$. In association with a ridge developed at about $85^{\circ} \mathrm{E}$, winds became relatively weak over major dust-source regions. During the Spring of 2001 (Fig. 10b), the planetary circulation exhibited a somewhat different picture, characterized by a zonal wavenumber 4 structure and the westward shift of EAT. The addition of the Alaska trough at about $150^{\circ} \mathrm{W}$ was responsible for the extra zonal wavenumber. In association with the westward shift of EAT to approximately $135^{\circ} \mathrm{E}$, jetstreams were displaced westward. This change introduced strong northwesterly flows over southern Mongolia and northern China to enhance the dry zone shown in Figs. 9b, d, and f. As documented in Gong et al. (2007), the zonal wavenumber change from 3 to 4 is possibly linked to the PNA (Pacific/North American) pattern independent of ENSO phase (Gong et al. 2007). They argued that, during a positive PNA index year (e.g., 2001), atmospheric circulation at $500 \mathrm{hPa}$ favors a wavier zonal structure through introducing a PNA-like wave train in the Asian-Pacific sector.

As discussed above, there appears to be a relation linking Asian dust storm activity to the position of EAT. To assess their relation quantitatively, yearly values of DAI and the position of EAT during $1995 \sim 2006$ are compared in Table 1. Also, to understand whether the strength of EAT matters, yearly values of EAT strength are displayed in the table. As shown in Table 1, the relation between Asian dust storm activity and the position of EAT is notable, with a cor- relation coefficient of -0.63 (satisfying the t-test at $95 \%$ confidence level). On the contrary, the relation between Asian dust storm activity and the strength of EAT appears to be quite weak with a correlation coefficient of only 0.14 .

\section{VARIABILITY OF SYNOPTIC CIRCULATION}

Although the position of EAT seems to explain a large part of the dust storm variations through introducing anomalous pressure dipoles over Asia (e.g., in 1997 and 2001), yet discrepancies are noted in some years (e.g., 1995 and 1998). Therefore, to what extent is the position of EAT related to the appearance of pressure dipole is an important issue that needs to be clarified beforehand. To address this issue, we use the method of singular value decomposition (SVD) to derive the dominant modes of synoptic circulation during $1995 \sim 2006$. The SVD method is a multivariate analysis technique that is often used to examine the climate variability from two observed fields involving spatial and temporal variations (Bretherton 1992).

Figure 11 shows the first and the second singular vectors (SVD1 and SVD2) derived from geopotential height and relative humidity at $1000 \mathrm{hPa}$ level. The SVD1 pattern (Fig. 11a), accounting for about $56 \%$ of the total variance, manifests a robust east-west oriented low-high dipole over Asia and a drier atmosphere over western and northern China. We note that a positive phase of SVD1 (i.e., low-high dipole) favors dust storm activity, whereas a negative phase (i.e., high-low dipole) disfavors dust storm activity. The time series of SVD1, however, shows that this dipole structure is significant (the magnitude of singular value $>0.49$ ) only in 1997 (negative phase), 2001, 2002, and 2006 (positive phase). When compared with Table 1, we find that a westward shift of EAT concurs well with the appearance of a low-high dipole structure in 2001, 2002, and 2006, while an eastward shift of EAT agrees well with the appearance of a high-low dipole structure in 1997.

The SVD2 pattern (Fig. 11b), accounting for only about $18 \%$ of the total variance, on the other hand, exhibits a distinct picture with an approximately reverse dipole structure and the moisture distribution. The time series of SDV2 shows that this dipole structure is significant (the magnitude of singular value $>0.35$ ) only in 1999 (positive phase) and 2006 (negative phase). Again, we find that an eastward shift of EAT concurs well with the high-low dipole structure in 1999, while a westward shift of EAT agrees well with the low-high dipole structure in 2006. We also find that the appearance of a dipole structure was not significant enough in 1995,1998 , or 2003. Such a result may explain why the relation between Asian dust storm activity and the position of EAT was so weak in the above years.

\footnotetext{
${ }^{1}$ The position of EAT is defined as the mean longitude of EAT averaged over $30 \sim 50^{\circ} \mathrm{N}$.
} 
(a) 500hPa average

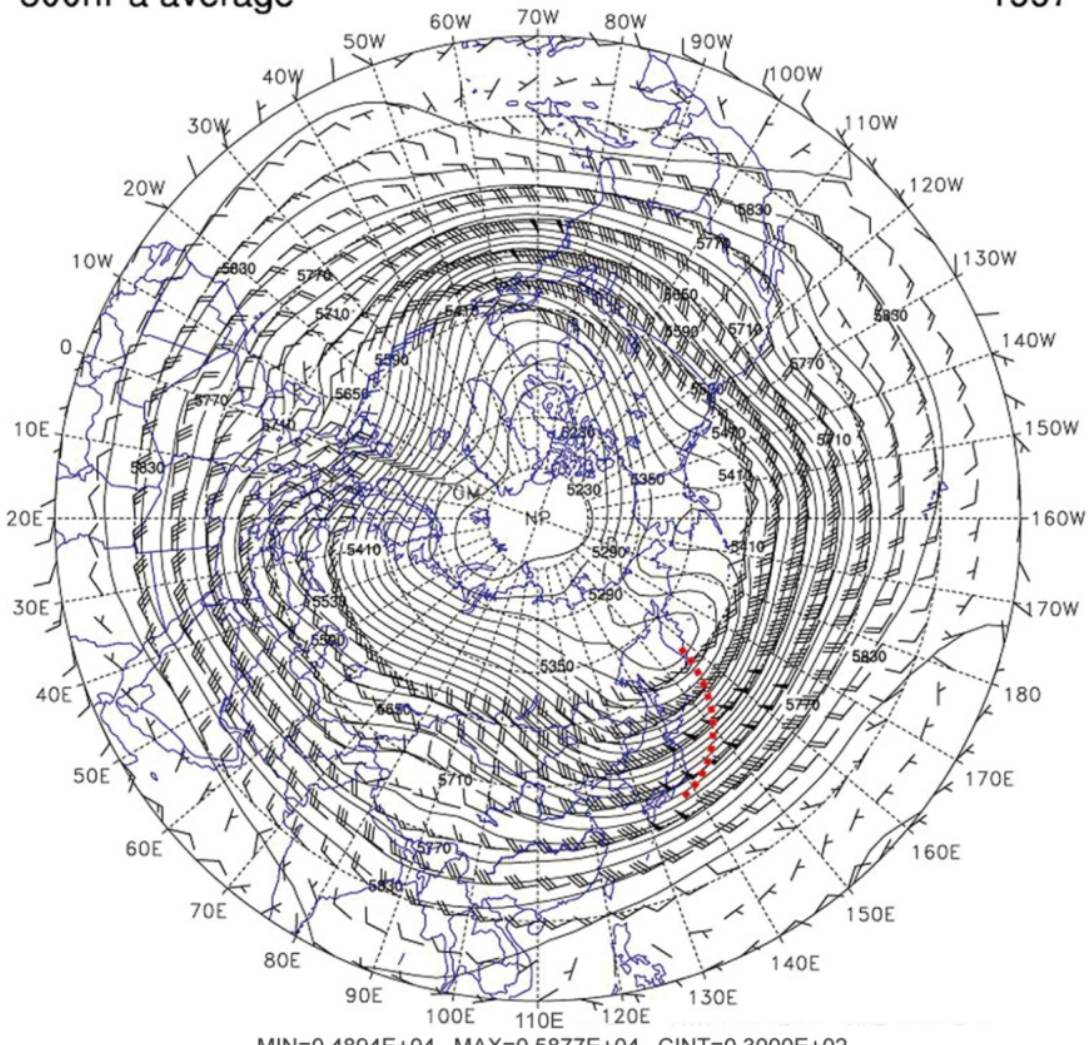

$M I N=0.4894 E+04 \quad M A X=0.5877 E+04 \quad C I N T=0.3000 E+02$

(b) 500hPa average

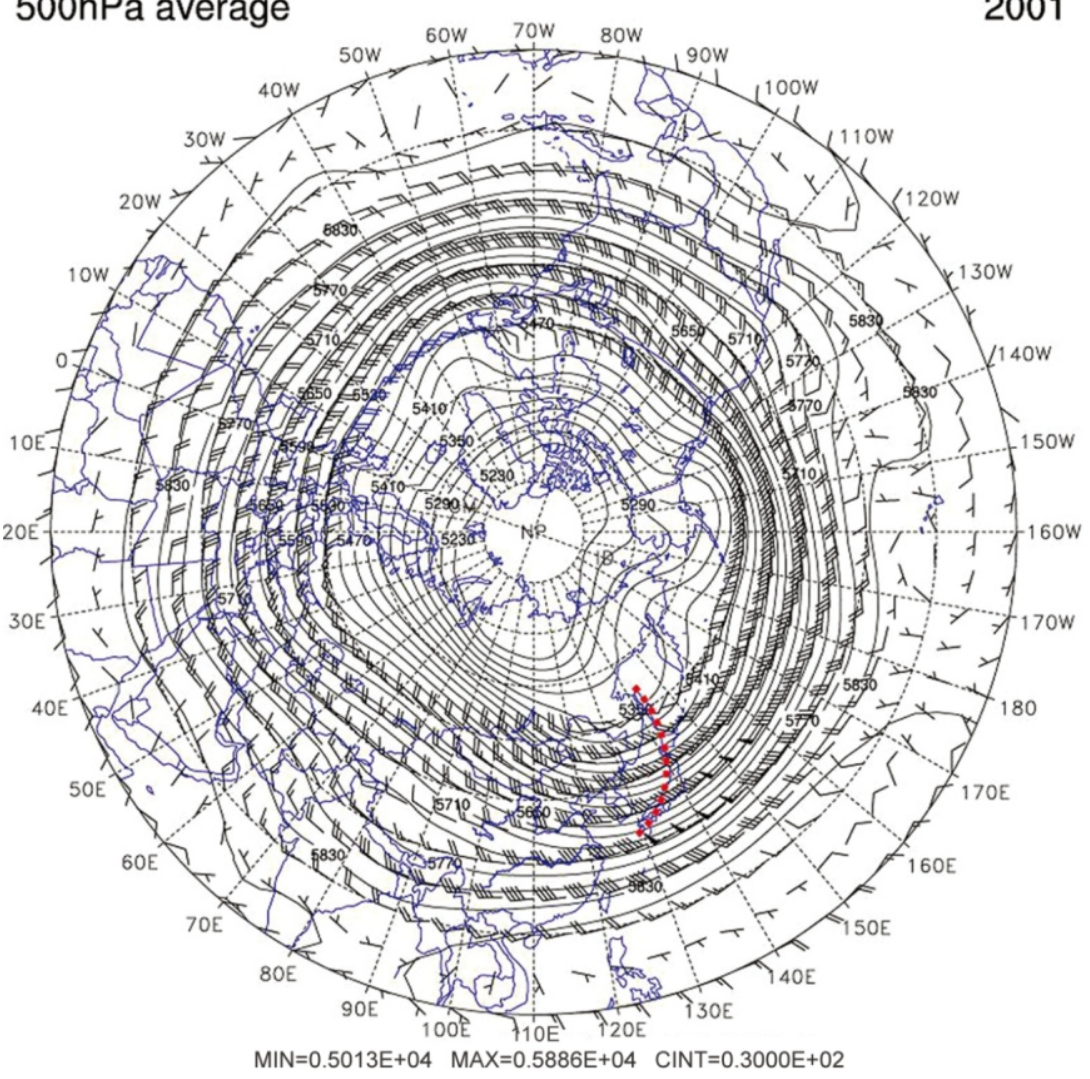

Fig. 10. General circulation patterns evaluated at $500 \mathrm{hPa}$ level during the Spring of 1997 (a) and 2001 (b). The East Asian Trough is denoted by a thick dashed line. Wind speeds are denoted by wind bars, with a short feather for 5 knots, a long feather for 10 knots, and a pennant for 50 knots. Contour interval of geopotential height is $30 \mathrm{~m}$. 
Table 1. A summary of the DAI, position of EAT (East Asian Trough), and strength of EAT during the Spring of 1995 2006. The EAT position is defined as the mean longitude of EAT averaged over $30 \sim 50^{\circ} \mathrm{N}$ while the strength of EAT is referred to as the mean geopotential height averaged over $\left(30 \sim 50^{\circ} \mathrm{N} / 130 \sim 150^{\circ} \mathrm{E}\right)$, both evaluated at $500 \mathrm{hPa}$ level. The relation between DAI and the position of EAT is statistically robust with $r=-0.63$ (t-test at $\alpha=0.05$ ), while the relation between DAI and the strength of EAT is statistically insignificant with $r=0.14$. The mean magnitudes of the above parameters are also listed at the right for reference.

\begin{tabular}{lccccccccccccc}
\hline & $\mathbf{1 9 9 5}$ & $\mathbf{1 9 9 6}$ & $\mathbf{1 9 9 7}$ & $\mathbf{1 9 9 8}$ & $\mathbf{1 9 9 9}$ & $\mathbf{2 0 0 0}$ & $\mathbf{2 0 0 1}$ & $\mathbf{2 0 0 2}$ & $\mathbf{2 0 0 3}$ & $\mathbf{2 0 0 4}$ & $\mathbf{2 0 0 5}$ & $\mathbf{2 0 0 6}$ & Mean \\
\hline Annual DAI (hr) & 12831 & 10206 & 4569 & 15933 & 7956 & 14400 & 26985 & 24231 & 8397 & 10605 & 10242 & 18414 & 13731 \\
Position of EAT ( $\left.{ }^{\circ} \mathbf{E}\right)$ & 135 & 145 & 150 & 153 & 150 & 136 & 135 & 138 & 150 & 145 & 140 & 138 & 143 \\
Strength of EAT (m) & 5529 & 5509 & 5531 & 5594 & 5534 & 5513 & 5524 & 5560 & 5559 & 5542 & 5517 & 5528 & 5537 \\
\hline
\end{tabular}

(a) SVD1 (1000 hPa HGT \& RHUM) SCF $=56.4743 \%$
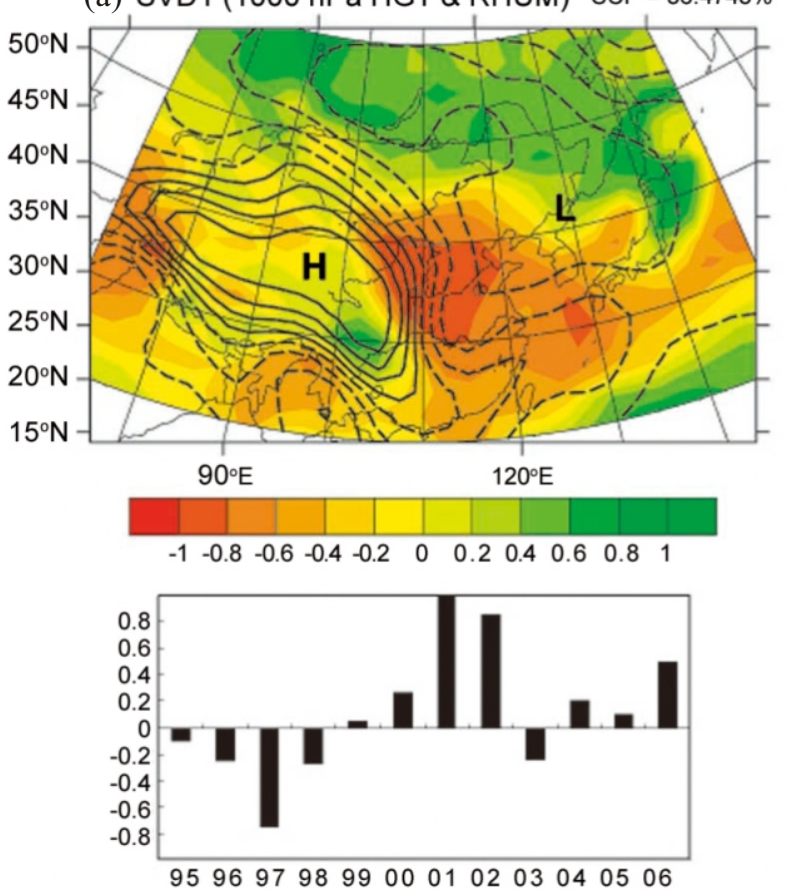

(b) SVD2 (1000 hPa HGT \& RHUM) SCF $=18.4216 \%$
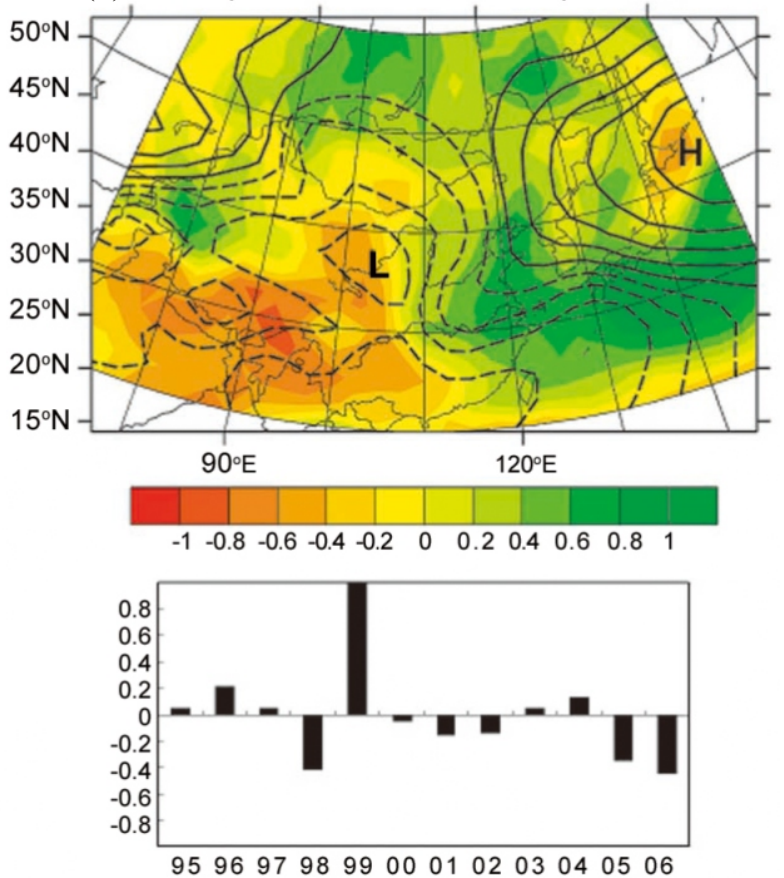

Fig. 11. The first (a) and the second (b) singular vectors of geopotential height (contours) and relative humidity (shadings) at $1000 \mathrm{hPa}$ level during the period $1995 \sim 2006$. The first singular vector (SVD1) accounts for about $56 \%$ of the total variance, while the second singular vector (SVD2) accounts for another $18 \%$. The time series plots of the corresponding singular values are displayed below the singular vector plots. All singular vectors and singular values are rescaled to have their magnitudes within $(-1 \sim 1)$. The standard deviation values of singular values for SVD1 and SVD2 are 0.49 and 0.35 , respectively.

Although the position of EAT may not be able to explain the entire Asian dust storm variations (in fact, no one can do that), the SVD analysis has shown that the relation between the position of EAT and the anomalous pressure dipoles is rather robust, at least in those years that Asian dust storm activity is particularly strong (e.g., 2001, 2002, and 2006) or weak (e.g., 1997 and 1999).

\section{TRAJECTORY ANALYSIS}

To project the potential transport paths of Asian dust aerosols from major dust-source regions, the forward trajectories calculated by the NOAA HYSPLIT model during the Spring of $1995 \sim 2006$ are analyzed. Since the errors of tra- jectory calculation tend to enlarge as the integration time increases, therefore only 4-day forward trajectory histories are adopted here (Dorling et al. 1992; Jorba et al. 2004). We note that a trajectory is best used as an indication of the airflow rather than the exact pathway of an air parcel. Thus, a large number of trajectories, in a climatological sense, simply represent a Lagarangian view of airstreams (Jorba et al. 2004; Wang 2005).

For convenience sake, we divide all seed trajectories into four clusters according to the direction of movement (Dorling et al. 1992). A trajectory is regarded as belonging to the east cluster if its 4-day mean position is located in the east quadrant. Similar approaches are applied to the remaining clusters. Figure 12 shows the clustered trajectory pat- 
terns with seed trajectories released from three major dustsource regions. For seed trajectories released from the Gobi Desert $\left(45^{\circ} \mathrm{N}, 105^{\circ} \mathrm{E}\right)$ (Fig. $\left.12 \mathrm{a}\right)$, the east cluster appears to be the dominant transport path, accounting for over $64 \%$ of the total trajectory number. The south cluster accounts for a sizable $20 \%$ of the total trajectory number, followed by a modest $11 \%$ in the west cluster and a fractional $5 \%$ in the north cluster. On average, the dominant east cluster has the longest transport distance and the lowest transport height among all clusters. Since the seed trajectories released from the Loess Plateau $\left(38^{\circ} \mathrm{N}, 108^{\circ} \mathrm{E}\right)$ (Fig. 12b) resemble the previous trajectory pattern (i.e., the Gobi Desert). We therefore neglect the discussion here for brevity.

For seed trajectories released from the Taklamakan

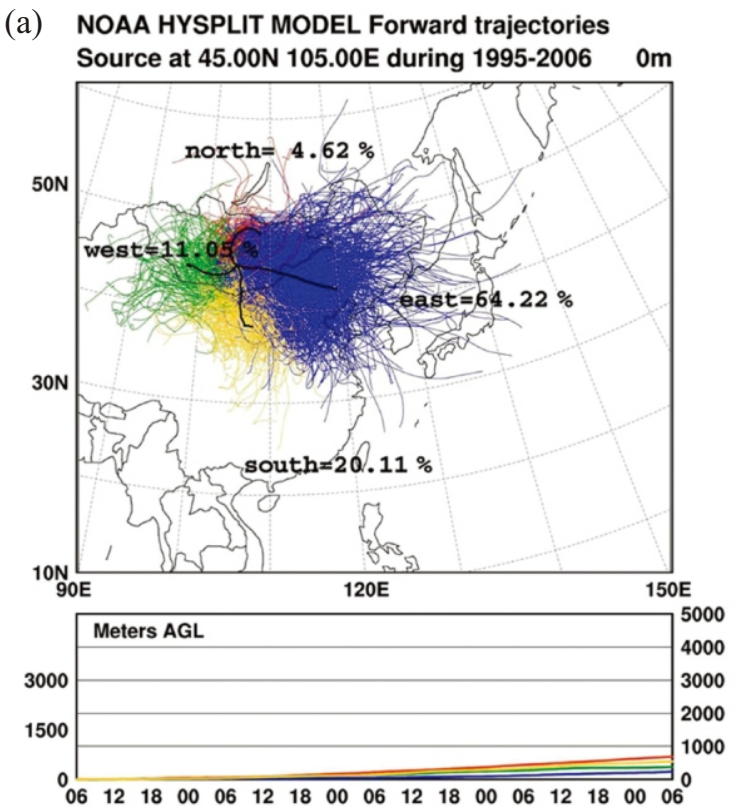

(c) NOAA HYSPLIT MODEL Forward trajectories Source at 39.00N 82.00E during 1995-2006
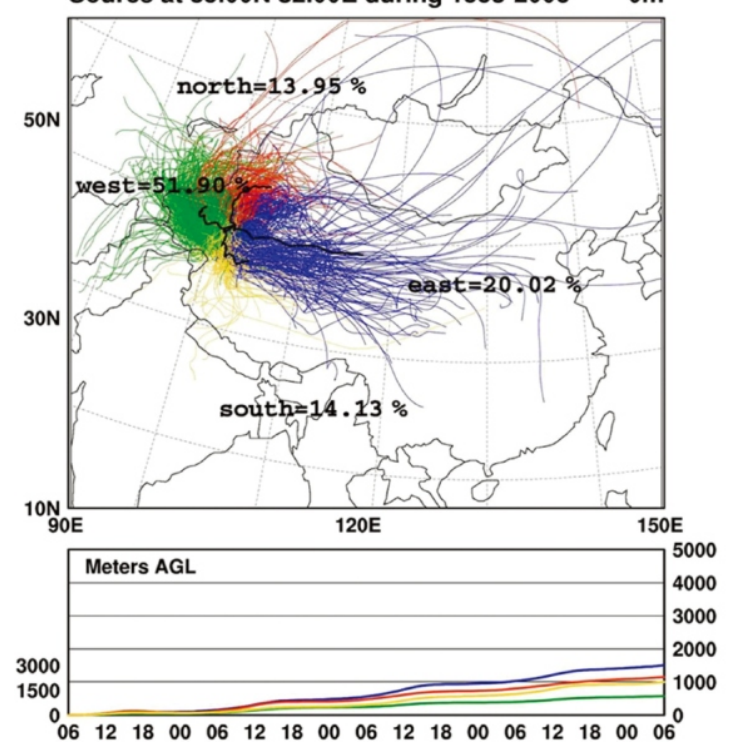

Desert $\left(39^{\circ} \mathrm{N}, 82^{\circ} \mathrm{E}\right)$ (Fig. 12c), a rather different picture appears. The west cluster now becomes the dominant path, accounting for nearly $52 \%$ of the total trajectory number, followed by $20 \%$ in the east cluster, and approximately $14 \%$ in the south and north clusters. On average, the dominant west cluster has the lowest transport height, yet the shortest transport distance compared to the remaining clusters. For the sake of clarity, Table 2 summarizes the percentage amounts of various clusters and their mean trajectory heights at $96 \mathrm{~h}$ for reference.

The results presented in Fig. 12 and Table 2 clearly suggest that dust aerosols arising from the Gobi Desert and the Loess Plateau are most likely to experience long-distance transport along the strong westerly flows, and to exert im- (b) NOAA HYSPLIT MODEL Forward trajectories Source at $38.00 \mathrm{~N}$ 108.00E during 1995-2006

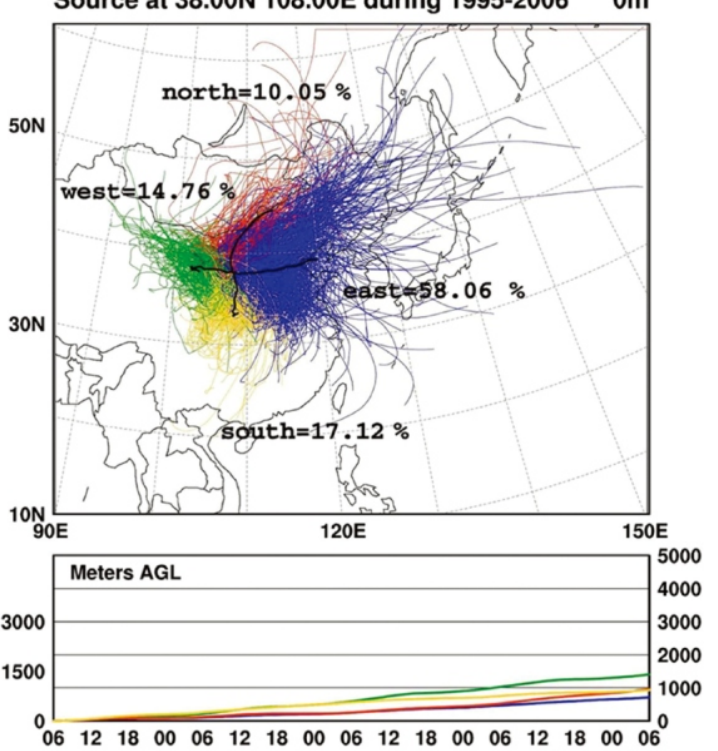

Fig. 12. The trajectory patterns with seed trajectories set free from the Gobi Desert (a), the Loess Plateau (b), and the Taklamakan Desert (c) during the Spring of 1995 2006. Four clusters of airstreams are identified in the figures: the east cluster (in blue), the south cluster (in yellow), the west cluster (in green), and the north cluster (in red). The mean trajectories (denoted by black curves) and the accumulative percentages for various clusters are also displayed in the figure for reference. The mean trajectory heights for various clusters during the 4-day period are also displayed below the trajectory plots. 
Table 2. The percentage amounts of various clusters for trajectories released from the Gobi Desert, Loess Plateau, and Taklamakan Desert, respectively. The mean trajectory heights at $96 \mathrm{~h}$ are displayed in the parentheses for comparison.

\begin{tabular}{llllc}
\hline & East Cluster & South Cluster & West Cluster & North Cluster \\
\hline Gobi Desert & $64.22 \%(220 \mathrm{~m})$ & $20.11 \%(537 \mathrm{~m})$ & $11.05 \%(365 \mathrm{~m})$ & $4.62 \%(685 \mathrm{~m})$ \\
Loess Plateau & $58.06 \%(683 \mathrm{~m})$ & $17.12 \%(902 \mathrm{~m})$ & $14.76 \%(1415 \mathrm{~m})$ & $10.05 \%(927 \mathrm{~m})$ \\
Taklamakan Desert & $20.02 \%(1463 \mathrm{~m})$ & $14.13 \%(1005 \mathrm{~m})$ & $51.90 \%(537 \mathrm{~m})$ & $13.95 \%(1112 \mathrm{~m})$ \\
\hline
\end{tabular}

pact on remote downstream areas. On the contrary, dust aerosols arising from the Taklamakan Desert tend to propagate westward, and to impact mainly the nearby regions. We note that the trajectory patterns shown in Fig. 12 agree well with the TOMS AI distribution (see Appendix A, Fig. A1) and the conjecture about Asian dust transport documented in Chen and Chen (1987) and Yu et al. (2002).

The cause responsible for such different trajectory patterns is quite straightforward. During the Spring, the Siberia-Mongolia high, centered around $\left(45 \sim 55^{\circ} \mathrm{N}, 90 \sim 100^{\circ} \mathrm{E}\right)$, is the dominant synoptic system controlling surface airflows over Asia (Wu and Chan 1997). Since the Gobi Desert and Loess Plateau are located to the southeast of the SiberiaMongolia high, the prevailing winds there are northwesterly in favor of eastward dust transport. Conversely, the Taklamakan Desert is located to the southwest of the SiberiaMongolia high, and the prevailing winds there are easterly in favor of westward dust transport. Moreover, because the Taklamakan Desert is surrounded by high mountains, dust transport out of the desert seems to be less possible except at higher levels $(>5000 \mathrm{~m})$ or in the eastward direction where an open area exists (Sun et al. 2001). In short, different geographical locations relative to the mean circulation and topography effect are responsible for different trajectory patterns shown in Fig. 12.

\section{CONCLUSIONS}

In this paper, land surface weather reports (also known as the "SYNOP data") are used to measure Asian dust storm activity during the period $1995 \sim 2006$. The SYNOP data provides in situ observations of dust events every 3 hours at 822 stations across Asia. A "dust activity index" (DAI) is defined in this study as a measure of the seasonal dust storm activity by summing up durations of all dust events occurring in Asia. To portray the circulation change associated with seasonal to interannual variations of dust storm activity, the NCEP/NCAR atmospheric data is analyzed.

Observations show that Spring (March, April, and May) stands out as the most active season for all dust events occurring in Asia, accounting for about two thirds of the annual DAI. Geographically, the Gobi Desert appears to be the most important source region for severe dust events (dust storm and blowing dust), followed by the Taklamakan Desert and the Loess Plateau. Although severe dust events tend to occur over dust-source regions, modest dust events (dust haze), however, can occur almost everywhere in Asia - a clear indication of dust transport across Asia.

During the Spring, the existence of a large-scale dry zone over mid-latitude Asia provides a favorable environment for dust storm occurrences and the subsequent dust transport. The background atmospheric circulation shows that the appearance of a quasi-stationary East Asian Trough (EAT) may play an important role in the maintenance of the dry zone. Specifically speaking, the dry zone is maintained by the Siberia-Mongolia high's dry and cold air that has been carried by the northwesterly flows behind EAT.

Asian dust storm activity manifested substantial interannual variations during $1995 \sim 2006$. A comparison between atmospheric circulation in 1997 and 2001 shows that the position of EAT might be able to explain such variations through introducing an anomalous pressure dipole over Asia. In a year when the EAT was shifted westward (e.g., 2001), an east-west oriented low-high dipole occurred. This low-high dipole immediately enhanced the prevailing northwesterly winds over southern Mongolia and northern China, resulting in a drier-than-normal atmosphere in favor of dust storm activity. Alternatively, in a year when the EAT was shifted eastward (e.g., 1997), a reverse dipole appeared. This high-low dipole directly weakened the prevailing northwesterly winds over southern Mongolia and northern China, resulting in a wetter-than-normal atmosphere disfavoring dust storm activity. A SVD analysis of the synoptic circulation further indicates that the relation between the appearance of anomalous pressure dipoles and the position of EAT is rather robust in 1997, 1999, 2001, 2002, and 2006, when dust storm activity is particularly strong or weak.

To project the potential paths of dust transport in Asia, a large number of trajectories derived from the NOAA HYSPLIT model are analyzed. The clustered trajectory patterns show that dust aerosols arising from Gobi Desert and Loess Plateau mostly experience eastward transport along the westerly flows. On the contrary, easterly flows occurring over the Taklamakan Desert incline dust aerosols to a slow westward propagation. Since long-range dust transport generally takes place along the strong westerly flows, the trajectory patterns suggest that the Gobi Desert and Loess Plateau are most likely to be the major sources of 
airborne dust aerosols in the Asian-Pacific region. Different geographical locations relative to the mean circulation and topography effect (i.e., high mountains surrounding the Taklamakan Desert) are responsible for such different transport patterns.

Acknowledgements This work was sponsored jointly by the National Science Council under NSC94-2111-M-034002 and NSC95-2111-M-034-003 and the Environmental Protection Administration under EPA-96-FA11-03-A166. The authors thank Prof. Ching-Hwang Liu (CCU) and the Central Weather Bureau for providing the original SYNOP data. The convenient use of on-line HYSPLIT model developed by US NOAA Air Resources Laboratory is highly appreciated. We would also like to thank the two anonymous reviewers for their critical comments and helpful suggestions.

\section{REFERENCES}

Bretherton, C. S., C. Smith, and J. M. Wallace, 1992: An intercomparison of methods for finding coupled patterns in climate data. J. Climate, 5, 541-560.

Chen, J. P., Z. Wang, C. Y. Young, F. Tsai, I. C. Tsai, G. J. Wang, W. C. Shieh, H. W. Lin, J .Y. Huang, and M .J. Lu, 2004: Simulations of Asian yellow dust incursion over Taiwan for the Spring of 2002 and 2003. Terr. Atmos. Ocean. Sci., 15, 949-981. [Link]

Chen, T. J. and H. J. Chen, 1987: Study on large-scale features of dust storm system in East Asia. Meteorol. Res., 10, 57-79.

Chiang, C. W., W. N. Chen, W. A. Liang, and J. B. Nee, 2004: Lidar measurements of Spring dusts in 2002 at Chung-Li $\left(25^{\circ} \mathrm{N}, 121^{\circ} \mathrm{E}\right)$. Terr. Atmos. Ocean. Sci., 15, 813-824. [Link]

Chou, C. C.-K., C. Y. Lin, T. K. Chen, S. C. Hsu, S. C. Lung, S. C. Liu, and C. Y. Young, 2004: Influence of long-range transport dust particles on local air quality: A case study on Asian dust episodes in Taipei during the Spring of 2002. Terr. Atmos. Ocean. Sci., 15, 881-899.

Collins, W. D., P. J. Rasch, B. E. Eaton, D. W. Fillmore, J. T. Kiehl, C. T. Beck, and C. S. Zender, 2002: Simulation of aerosol distributions and radiative forcing for INDOEX: Regional climate impacts. J. Geophys. Res., 107, 8028, doi: 10.1029/2000JD000032. [Link]

Djuric, D., 1994: Weather Analysis, Prentice-Hall, Inc, 304 pp.

Dorling, S. R., T. D. Davies, and C. E. Pierce, 1992: Cluster analysis: A technique for estimating the synoptic meteorological controls on air and precipitation chemistry-Method and applications. Atmos. Environ., 26, 2575-2581.

Draxler, R. R. and G. D. Hess, 1998: An overview of the HYSPLIT_4 modeling system for trajectories, dispersion, and deposition. Aust. Meteorol. Mag., 47, 295-308.

Fang, M., M. Zheng, F. Wang, K. S. Chim, and S. C. Kot, 1999: The long range transport of aerosols from northern China to Hong Kong - a multi-technique study. Atmos. Environ., 33, 1803-1817, doi: 10.1016/S1352-2310(98)00318-5. [Link]

Gao, T., L. Su, Q. Ma, H. Li, X. Li, and X. Yu, 2003: Climatic analyses on increasing dust storm frequency in Springs of 2000 and 2001 in Inner Mongolia. Int. J. Climatol., 23, 1743-1755, doi: 10.1002/joc.970. [Link]

Glickman, T. S., 1999: Glossary of Meteorology. American Meteorological Society, $850 \mathrm{pp}$.

Gong, D. Y., R. Mao, and Y. D. Fan, 2006: East Asian dust storm and weather disturbance: Possible links to the Artic Oscillation. Int. J. Climatol., 26, 1379-1396, doi: 10.1002/ joc.1324. [Link]

Gong, D. Y., R. Mao, P. J. Shi, and Y. D. Fan, 2007: Correlation between East Asian dust storm frequency and PNA. Geophys. Res. Lett., 34, L14710, doi: 10.1029/2007GL029944. [Link]

Goudie, A. and N. J. Middleton, 1992: The changing frequency of dust storms through time. Clim. Change, 20, 197-225, doi: 10.1007/BF00139839. [Link]

Griffin, D. W. and C. A. Kellogg, 2004: Dust storms and their impact on ocean and human health: Dust in earth's atmosphere. EcoHealth, 1, 284-295, doi: 10.1007/s10393-0040120-8. [Link]

Hacker, J. P., I. G. McKendry, and R. B. Stull, 2001: Modeled downward transport of a passive tracer over western north America during an Asian dust event in April 1998. J. Appl. Meteorol., 40, 1617-1628, doi: 10.1175/1520-0450(2001) $040<1617$ :MDTOAP $>2.0 . \mathrm{CO} ; 2$. [Link]

Haywood, J. M. and O. Boucher, 2000: Estimates of the direct and indirect radiative forcing due to tropospheric aerosol: A review. Rev. Geophys., 38, 513-543, doi: 10.1029/1999 RG000078. [Link]

Husar, R. B., D. M. Tratt, B. A. Schichtel, S. R. Falke, F. Li, D. Jaffe, S. Gassó, T. Gill, N. S. Laulainen, F. Lu, M. C. Reheis, Y. Chun, D. Westphal, B. N. Holben, C. Gueymard, I. McKendry, N. Kuring, G. C. Feldman, C. McClain, R. J. Frouin, J. Merrill, D. DuBois, F. Vignola, T. Murayama, S. Nickovic, W. E. Wilson, K. Sassen, N. Sugimoto, and W. C. Malm, 2001: Asian dust events of April 1998. J. Geophy. Res., 106, 18317-18330, doi: 10.1029/2000JD900788. [Link]

Iwasaka, Y., H. Minoura, and K. Nagaya, 1983: The transport and spatial scale of Asian dust-storm clouds: A case study of the dust-storm event of April 1979. Tellus, 35B, 189196.

Jhun, J.-G. and E.-J. Lee, 2004: A new East Asian Winter Monsoon index and associated characteristics of the winter monsoon. J. Climate, 17, 711-726, doi: 10.1175/15200442(2004)017<0711:ANEAWM >2.0.CO;2. [Link]

Jorba, O., C. Perez, F. Rocadenbosch, and J. M. Baldasano, 2004: Cluster analysis of 4-day back trajectories arriving in the Barcelona area, Spain, from 1997 to 2002. J. Appl. Meteorol., 43, 887-901, doi: 10.1175/1520-0450(2004) 043<0887:CAODBT $>2.0 . \mathrm{CO} ; 2$. [Link] 
Kalnay, E., M. Kanamitsu, R. Kistler, W. Collins, D. Deaven, L. Gandin, M. Iredell, S. Saha, G. White, J. Woollen, Y. Zhu, M. Chelliah, W. Ebisuzaki, W. Higgins, J. Janowiak, K. C. Mo, C. Ropelewske, J. Wang, A. Leetmaa, R. Reynolds, R. Jenne, and D. Joseph, 1996: The NCEP/NCAR 40-Year reanalysis project. Bull. Amer. Meteorol. Soc., 77, 437471, doi: 10.1175/1520-0477(1996)077<0437:TNYRP> 2.0.CO;2. [Link]

Kaufman, Y. J., D. Tanré, and O. Boucher, 2002: A satellite view of aerosols in the climate system. Nature, 419, 215223, doi: 10.1038/nature01091. [Link]

Lin, C .Y., S. C. Liu, C. C.-K. Chou, T. H. Liu, C. T. Lee, C. S. Yuan, C. J. Shiu, and C. Y. Young, 2004: Long-range transport of Asian dust and air pollutants to Taiwan. Terr. Atmos. Ocean. Sci., 15, 759-784. [Link]

Lin, T. S. and J. Y. Yu, 2005: A case study of the "Yellow Rain" occurring in northern Taiwan on March 12, 1995. Atmos. Sci., 33, 143-160. (in Chinese)

Liu, G. R. and T. H. Lin, 2004: Application of geostationary satellite observations for monitoring dust storms of Asia. Terr. Atmos. Ocean. Sci., 15, 825-837. [Link]

Nee, J. B., C. W. Chiang, H. Hu, S. Hu, and J. Y. Yu, 2007: Lidar measurements of Asian dust storms and dust cloud interactions. J. Geophy. Res., 112, D15202, doi: 10.1029/2007 JD008476. [Link]

Nemani, R. R. and S. W. Running, 1995: Satellite monitoring of global land cover changes and their impact on climate. Clim. Change, 31, 395-413, doi: 10.1007/BF01095154. [Link]

Qian, W., L. Quan, and S. Shi, 2002: Variations of the dust storm in China and its climate control. J. Climate, 15, 1216-1229, doi: 10.1175/1520-0442(2002)015<1216: VOTDSI $>2.0 . \mathrm{CO} ; 2$. [Link]

Ramankutty, N. and J. Foley, 1999: Estimating historical changes in global land cover: Croplands from 1700 to 1992. Global Biogeochem. Cycles, 13, 997-1028, doi: 10.1029/1999GB 900046. [Link]

Sun, J. M., M. Y. Zhang, and T. S. Liu, 2001: Spatial and temporal characteristics of dust storms in China and its surrounding regions, 1960-1999: Relations to source area and climate. J. Geophy. Res., 106, 10325-10334, doi: 10.1029/ 2000JD900665. [Link]

Tien, S.-F., M. Inoue, and M. Du, 2007: Influence of dust storm frequency in northern China on fluctuations of Asian dust frequency observed in Japan. SOLA, 3, 121-124, doi: 10.2151/sola.2007-031. [Link]

Uno, I., H. Amano, S. Emori, K. Kinoshita, I. Matsui, and N. Sugimoto, 2001: Trans-Pacific yellow sand transport observed in April 1998: A numerical simulation. J. Geophy. Res., 106 (D16), 18331-18344, doi: 10.1029/2000JD 900748. [Link]

Wang, K. Y., 2005: A 9-year climatology of airstreams in East Asia and implications for the transport of pollutants and downstream impacts. J. Geophys. Res., 110, D07306, doi: 10.1029/2004JD005326. [Link]
Wei, W., H. Zhou, Y. Shi, O. Abe, and K. Kai, 2005: Climatic and environmental changes in the source areas of dust storms in Xinjian, China, during the last 50 years. Water Air Soil Pollut., 5, 207-216, doi: 10.1007/s11267-0050736-x. [Link]

Wu, M. C. and J. C. L. Chan, 1997: Upper-level features associated with winter monsoon surges over South China. Mon. Weather Rev., 125, 317-340, doi: 10.1175/15200493(1997)125<0317:ULFAWW>2.0.CO;2. [Link]

Yoshino, M., 2002: Climatology of yellow sand (Asian sand, Asian dust or Kosa) in East Asia. Sci. China Ser. D-Earth Sci., 45, 59-70.

Yu, J. Y., Y. M. Cho, and J. Y. Tu, 2002: On the space-time characteristics of East Asian dust storms. J. Environ. Prot., 25, 178-198. (in Chinese)

Zhang, X. Y., S. L. Gong, T. L. Zhao, R. Arimoto, Y. Q. Wang, and Z. J. Zhou, 2003: Sources of Asian dust and role of climate change versus desertification in Asian dust emission. Geophys. Res. Lett., 30, 2272, doi: 10.1029/2003GL 018206. [Link]

Zhao, B. and X. Yu, 1990: On eastern Asian dust storm. $A d v$. Atmos. Sci., 7, 11-26, doi: 10.1007/BF02919164. [Link]

Zhao, X., Z. Wang, G. Zhuang, and C. Pang, 2007: Model study on the transport and mixing of dust aerosols and pollutants during an Asian dust storm in March 2002. Terr. Atmos. Ocean. Sci., 18, 437-457, doi: 10.3319/TAO.2007.18.3. 437(EA). [Link]

\section{APPENDIX A: INTERANNUAL VARIABILITY OF TOMS AEROSOL INDEX}

To test the sensitivity of DAI (Dust Activity Index) against satellite observations, the aerosol index (AI) data from NASA TOMS (Total Ozone Mapping Spectrometer) is analyzed here. The AI is determined by the UV (ultraviolet) radiometry measurements of TOMS sensor. These measures are related to aerosol concentration within a particular column of atmosphere and aerosols at low altitudes generally have a lower AI value than an equivalent depth of aerosols at higher altitudes.

Figure A1 shows the first EOF (Empirical Orthogonal Function) pattern of TOMS AI and the corresponding time series of principle component during $1979 \sim 2005$. The first EOF accounts for a remarkable $61 \%$ of the total variance with the peak amplitudes occurring regularly in Spring. Although TOMS AI already shows some degree of interannual variability similar to the DAI, however, its year-to-year variability seems to be far below than those in DAI (see Fig. 3 for comparison). The underestimation of aerosol concentration at low altitudes is possibly responsible for the much weaker year-to-year variations shown in TOMS AI.

In addition, two centers of significant $\mathrm{AI}$ are found in Fig. A1: one over the western part of China and the other over the eastern part of China. We note that the latter center 
is not situated over major dust-source regions such as the Gobi Desert and Loess Plateau. Instead, it is located to the east of the aforementioned regions. Alternatively, the former center is situated approximately over the Taklamakan Desert. The results shown in Fig. A1 confirm that dust aerosols entrained to the air form Gobi Desert and Loess Plateau tend to propagate eastward along the westerly flows, while dust aerosols entrained to the air from Taklamakan Desert are confined in the nearby region, which is consistent with the results discussed in section 6 .
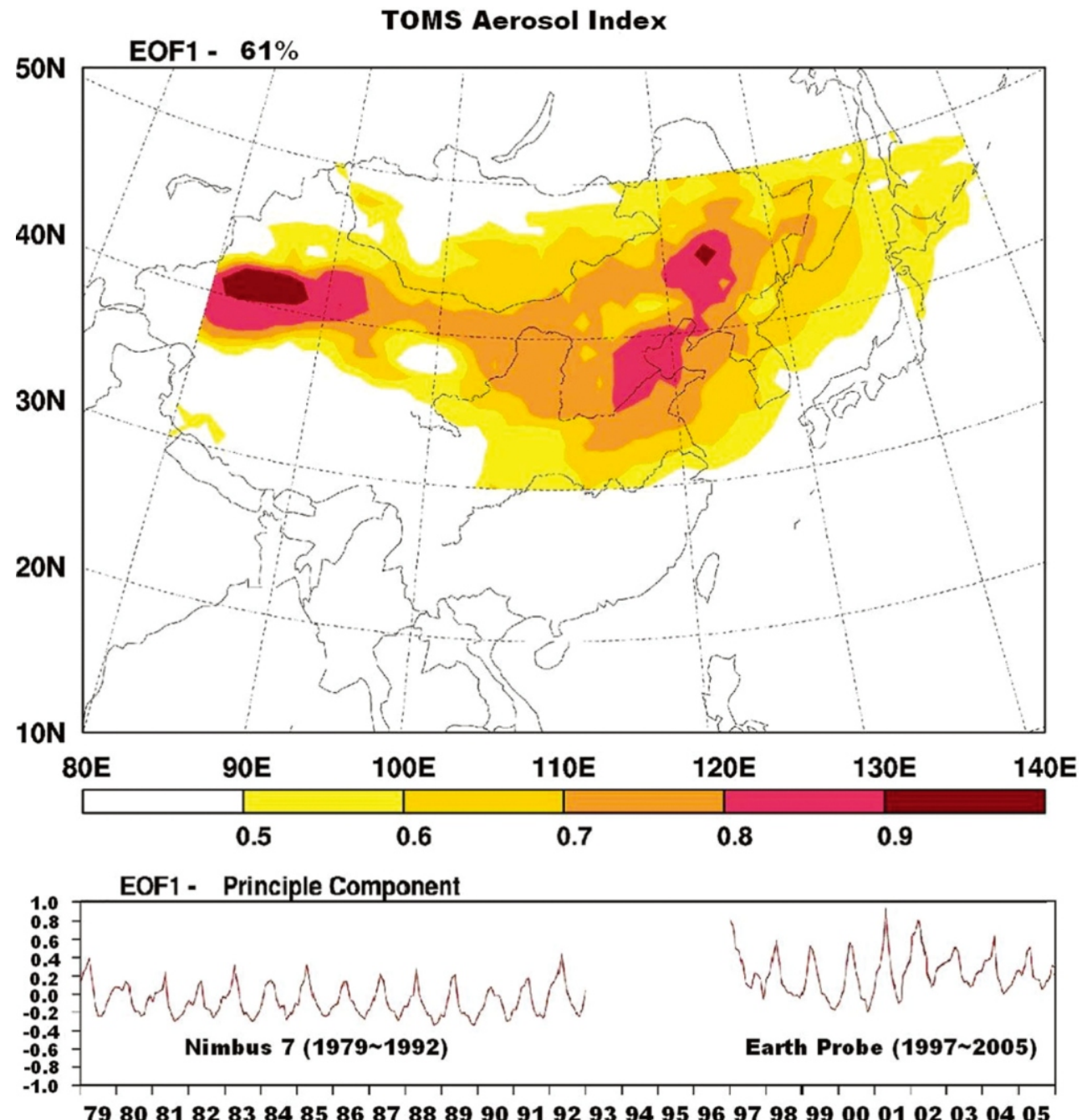

Fig. A1. The first EOF pattern of TOMS AI (aerosol index) over the domain $\left(30 \sim 50^{\circ} \mathrm{N}, 80 \sim 140^{\circ} \mathrm{E}\right)$ and the associated time series of its principle component during the period $1979 \sim 2005$. The first EOF accounts for about $61 \%$ of the total variance. Here, eigenvectors and eigenvalues are rescaled to have their magnitudes within $(-1 \sim 1)$. The gap shown in the time series plot during $1993 \sim 1996$ denotes the period without satellite observations. 